\title{
Contribuições da assistência de enfermagem no acolhimento de adolescentes com ideações suicidas
}

\author{
Contributions of nursing care in welcoming adolescents with suicidal ideation \\ Contribuciones de los cuidados de enfermería en la acogida de adolescentes con ideación suicida
}

Antonio Francisco da Costa Machado

ORCID: https://orcid.org/0000-0003-0111-8775

Centro Universitário Santo Agostinho, Brasil

E-mail: tony94machado30@gmail.com

João Vitor Martins Amorim

ORCID: https://orcid.org/0000-0002-5126-8109

Centro Universitário Santo Agostinho, Brasil

E-mail: mjoaovitor783@gmail.com

Maria Bianca e Silva Lima

ORCID: https://orcid.org/0000-0002-9175-0434

Centro Universitário Santo Agostinho, Brasil

E-mail: mariabianca10075@gmail.com

Woodyson Welson Barros da Silva Batista

ORCID: https://orcid.org/0000-0002-8451-9795

Universidade Federal do Piauí, Brasil

E-mail: woodywb2020@ outlook.com

Geovana Maria Rodrigues de Sousa

ORCID: https://orcid.org/0000-0001-6398-8560

Centro Universitário Santo Agostinho, Brasil

E-mail: geovanamaria08@hotmail.com

Isabella Maria Silva Feitoza

ORCID: https://orcid.org/0000-0003-2337-2635

Faculdade Estácio de Sá, Brasil

E-mail: isabellam9920@gmail.com

Tagila Andreia Viana dos Santos

ORCID: https://orcid.org/0000-0001-9812-4295 
Camilla Julianne Loureiro de Oliveira Andrade ORCID: https://orcid.org/0000-0002-0747-3172 Centro Universitário Santo Agostinho, Brasil E-mail: camillaandrade@hotmail.com

Maria Celita Vieira Pedreira

ORCID: https://orcid.org/0000-0001-6287-6532 Centro Universitário Unifapi, Brasil E-mail: mariacelitaaa@gmail.com

Karolini de Oliveira Carvalho

ORCID: https://orcid.org/0000-0002-2014-2589 Fundação Educacional de Fernandópolis, Brasil

E-mail: karolini.carvalho2307@gmail.com

Ana Vitória Galera Rodrigues

ORCID: https://orcid.org/0000-0003-1450-7219 Fundação Educacional de Fernandópolis, Brasil

E-mail: anagaleraviih@gmail.com

Cynthia Patrícia de Sousa Cardoso

ORCID: https://orcid.org/0000-0002-6504-1394

Centro Universitário Santo Agostinho, Brasil

E-mail: patriciacynthia89@gmail.com

Layanne Cavalcante de Moura

ORCID: https://orcid.org/0000-0003-2781-1076 Centro Universitário Unifacid, Brasil

E-mail: layannecavalcante@ hotmail.com

Gustavo Baroni Araujo

ORCID: https://orcid.org/0000-0002-3162-7477

Universidade Estadual de Londrina, Brasil E-mail: gustavobaroni13@ hotmail.com

Tércio Macêdo de Andrade

ORCID: https://orcid.org/0000-0002-7441-4447

Centro Universitário Maurício de Nassau, Brasil E-mail: tercio.andrade@hotmail.com

\title{
Resumo
}

Analisar as evidências científicas publicadas sobre as contribuições da assistência de enfermagem no acolhimento de adolescentes com ideações suicidas. O presente estudo trata de uma revisão bibliográfica do método revisão integrativa da literatura, realizado nos meses entre janeiro a junho de 2021. A busca efetuou-se, através da Plataforma da Biblioteca Virtual em Saúde - BVS, utilizando as bases de dados LILACS, BDENF, e por meio da SCIELO. Aderindo-se através dos descritores/palavras chaves: "Cuidados de Enfermagem", "Suicídio", "Adolescente", combinados com o operador booleano "AND". Entre os adolescentes, os principais fatores de risco para o suicídio são: idade, tentativa prévia, transtorno de humor, depressão, abuso de drogas lícitas e ilícitas, ausência de apoio familiar, história familiar de doenças psiquiátricas, história familiar de comportamento suicida, doença física grave e/ou crônica, eventos estressores, orientação sexual. A enfermagem é responsável pelos cuidados iniciais ao paciente que tenta suicídio, além disso, devido à essência de sua atividade, que é o cuidado, permanece por mais tempo em contato direto com o ser assistido. A equipe de enfermagem possui potencialidade para auxiliar na prevenção de novas tentativas de suicídio. Entende-se, que os profissionais de enfermagem têm papel muito importante no acolhimento dos pacientes com risco ao suicídio e dos familiares. Para isso utilizam ferramentas e estratégias como: o exame do estado mental, a avaliação e a classificação de risco, o acolhimento do paciente em local seguro para ambos, uma rede de apoio juntamente a serviços especializados, familiares/cuidadores e administração de terapia medicamentosa, quando necessário, além de visitas domiciliares.

Palavras-chave: Cuidados de enfermagem; Suicídio; Adolescente.

\begin{abstract}
To analyze published scientific evidence on the contributions of nursing care in welcoming adolescents with suicidal ideation. This study is a literature review of the integrative literature review method, carried out in the months between January and June 2021. The search was carried out through the Virtual Health Library Platform - VHL, using the LILACS, BDENF databases, through SCIELO. Adhering through the descriptors/key words: "Nursing Care", "Suicide", "Adolescent", combined with the Boolean operator "AND". Among adolescents, the main risk factors for suicide are: age, previous attempt, mood disorder, depression, abuse of legal and illegal drugs, lack of family support, family history of psychiatric illnesses, family history of suicidal behavior, illness severe and/or chronic physical, stressful events, sexual orientation. Nursing is responsible for the initial care of patients who attempt suicide, in addition, due to the essence of their activity, which is care, they remain in direct contact with the person being assisted for longer. The nursing team has the potential to help prevent new suicide attempts. It is understood that nursing professionals have a very important role in welcoming patients at risk of suicide and their families. For this, they use tools and strategies such as: mental state examination, risk assessment and classification, patient care in a safe place
\end{abstract}


for both, a support network together with specialized services, family members/caregivers and administration of drug therapy, when necessary, in addition to home visits.

Keywords: Nursing care; Suicide; Adolescent.

\section{Resumen}

Analizar la evidencia científica publicada sobre las contribuciones del cuidado de enfermería en la acogida de adolescentes con ideación suicida. Este estudio es una revisión bibliográfica del método de revisión integradora de la literatura, realizada en los meses de enero a junio de 2021. La búsqueda se realizó a través de la Plataforma Biblioteca Virtual en Salud - BVS, utilizando las bases de datos LILACS, BDENF, a través de SCIELO. Cumpliendo con los descriptores / palabras clave: "Atención de enfermería", "Suicidio", "Adolescente", combinado con el operador booleano "Y". Entre los adolescentes, los principales factores de riesgo de suicidio son: edad, intento previo, trastorno del estado de ánimo, depresión, abuso de drogas legales e ilegales, falta de apoyo familiar, antecedentes familiares de enfermedades psiquiátricas, antecedentes familiares de conducta suicida, enfermedad grave y / o eventos físicos crónicos, estresantes, orientación sexual. Enfermería se encarga de la atención inicial de los pacientes que intentan suicidarse, además, debido a la esencia de su actividad, que es la atención, permanecen en contacto directo con la persona a la que se atiende durante más tiempo. El equipo de enfermería tiene el potencial de ayudar a prevenir nuevos intentos de suicidio. Se entiende que los profesionales de enfermería tienen un papel muy importante en la acogida de pacientes en riesgo de suicidio y sus familias. Para ello, utilizan herramientas y estrategias como: examen del estado mental, evaluación y clasificación de riesgos, atención al paciente en un lugar seguro para ambos, una red de apoyo junto con servicios especializados, familiares / cuidadores y administración de farmacoterapia, cuando sea necesario, además de las visitas domiciliarias.

Palabras clave: Cuidado de enfermera; Suicidio; Adolescente.

\section{Introdução}

A adolescência é compreendida como um processo transitório importante do desenvolvimento humano entre a fase da infância e a fase adulta. Segundo a Organização Mundial da Saúde (2005), a adolescência configura-se no período entre 10 e 19 anos. Assim, é entendida como uma fase de muitas mudanças fisiológicas e psicológicas, além das questões afetivas, familiares e sociais. Neste sentido, o adolescente se torna mais vulnerável a influências. Além de está desenvolvendo sua autonomia, os jovens adolescentes preocupam-se com seu papel na sociedade, projetando seus sonhos, planos, hobbies, estudos, profissão, grupos sociais e a construção de sua identidade (Cardoso, \& Cecconello, 2019).

Segundo Cardoso, e Cecconello (2019), nesse processo de construção da identidade da saída da infância e entrada na vida adulta, a transição do adolescente por vários contextos pode levar ao aparecimento de comportamentos de risco, como abuso de substâncias psicoativas, comportamento sexual de risco e violência.

A adolescência é um período de complexo desenvolvimento, durante o qual os indivíduos podem assumir diversos hábitos considerados de risco, dentre eles o comportamento suicida, que abrange a ideação suicida, tentativas de suicídio e o suicídio propriamente dito. Entre adolescentes, os fatores que favorecem o comportamento suicida são: pobreza, violências, diferenças econômicas, conturbação familiar, uso de substâncias psicoativas, pouco suporte social, decepção amorosa, homossexualidade, solidão, histórico familiar de comportamento suicida, tentativa prévia e ideação suicida (Sousa et al., 2020).

A adolescência é uma parte do processo natural do crescimento humano, configurando-se como um período em que o adolescente não é adulto, mas também não é considerado mais uma criança. Faz-se necessário que, durante essa fase, o indivíduo amplie e possa desenvolver suas capacidades para adquirir experiências e valores fundamentais para adaptar-se à fase adulta. É nessa etapa que a adolescência pode reverter-se em uma fase de conflitos que, muitas vezes, torna os comportamentos arriscados para a vida do indivíduo, incluindo a problemática das ideações suicidas e/ou até mesmo do ato em si (Fernandes et al., 2020)

Segundo Oliveira et al. (2016), o suicídio é um fenômeno determinado bio-psicologicamente influenciado por aspectos socioculturais que cercam cada indivíduo. Trata-se de um percurso que vai desde a motivação e ideação suicida até o planejamento do método e a autoagressão. 
O suicídio é a segunda causa de morte nos adolescentes dos 15 aos 19 anos de idade sendo mesmo responsável por $85 \%$ das mortes nesta faixa etária, em todo o mundo. E atualmente existem evidências relativas a um aumento do número de casos. Estima-se ainda, que por cada suicídio consumado em adolescentes, ocorre entre 100 e 200 tentativas de suicídio, o que alerta para a natureza repetitiva destes comportamentos, tornando-os maiores preditores de comportamentos futuros e de eventual morte por suicídio (Simões, Santos, \& Martinho, 2021).

De acordo com Fernandes et al. (2020), o suicídio é um ato intencional do indivíduo para extinguir a própria vida. É um dano sério que vem aumentando em níveis preocupantes, fato que o torna uma importante questão para a saúde pública. A conduta suicida traz uma inquietação, especialmente, entre os profissionais da área de saúde.

Durante o primeiro contato entre a equipe de enfermagem e o paciente com pensamento suicida, o acolhimento é fundamental para consolidar laços afetivos. Esse contato proporciona uma excelente oportunidade para que os profissionais identifiquem os riscos de suicídio, usando estratégias e prevenção para minimizar o desejo de autoextermínio. Além disso, os profissionais de enfermagem são agentes fundamentais para identificar os riscos de suicídio. Através da prevenção, acolhimento e escuta do paciente, orientação aos familiares da vítima, do agendamento de consultas, da realização do acompanhamento, por meio de visitas domiciliares e/ou consultas de enfermagem, identificação do risco para o suicídio, auxílio no uso das medicações, conscientização da comunidade sobre problemas de saúde mental, verificação de história prévia de comportamento suicida e incentivo à socialização (Marcal, \& Gonçalves, 2020).

Diante da temática em discussão, surge como questão norteadora do estudo: "Quais as contribuições da assistência de enfermagem no acolhimento de adolescentes com ideações suicidas"? Assim, o objetivo do presente estudo é analisar as evidências científicas publicadas sobre as contribuições da assistência de enfermagem no acolhimento de adolescentes com ideações suicidas.

A realização do presente estudo relacionado à temática, é essencial para a construção coletiva do conhecimento, pois, o estudo possibilita a sociedade acadêmica e cientifica a ampliar o conhecimento sobre as contribuições da assistência de enfermagem no acolhimento de adolescentes com ideações suicidas. Desse modo, o estudo trará contribuições pertinentes, na medida em que acrescentará as evidências científicas discussões relevantes a respeito dessa temática tão importante.

\section{Metodologia}

O presente estudo trata de uma revisão bibliográfica do método revisão integrativa da literatura, realizado nos meses entre janeiro a junho de 2021. A revisão configura-se, portanto, como um tipo de revisão da literatura que reúne achados de estudos desenvolvidos mediante diferentes metodologias, permitindo aos revisores sintetizar resultados sem ferir a filiação epistemológica dos estudos empíricos incluídos. Para que esse processo concretize-se de maneira lógica, isenta de desatinos epistemológicos, a revisão requer que os revisores procedam à análise e à síntese dos dados primários de forma sistemática e rigorosa (Soares et al., 2014).

A revisão da literatura serve para reconhecer a unidade e a diversidade interpretativa existente no eixo temático em que se insere o problema em estudo, para ampliar, ramificar a análise interpretativa, bem como para compor as abstrações e sínteses que qualquer pesquisa requer colaborando para a coerência nas argumentações do pesquisador. Nesse sentido, a revisão integrativa é um método que tem como finalidade reunir e sintetizar resultados de pesquisas sobre um delimitado tema ou questão, de maneira sistemática e ordenada e abrangente, contribuindo para o aprofundamento do conhecimento do tema investigado (Ferenhof \& Fernandes, 2016).

O processo de revisão da literatura requer a elaboração de uma síntese pautada em diferentes tópicos, capazes de criar uma ampla compreensão sobre o conhecimento. A revisão da literatura é um primeiro passo para a construção do 
conhecimento científico, pois é através desse processo que novas teorias surgem, bem como são reconhecidas lacunas e oportunidades para o surgimento de pesquisas num assunto específico (Botelho, Cunha, \& Macedo, 2011).

A revisão integrativa é uma ferramenta de investigação que permite à procura, a avaliação crítica e a síntese de evidências disponíveis sobre o tema investigado, em que o produto final é o estado do conhecimento, a implementação de intervenções efetivas na prestação de cuidados e na redução de custos. Além disso, permite a identificação de fragilidades, que poderão conduzir ao desenvolvimento de futuras investigações (Sousa, Marques-Vieira, Severino, \& Antunes, 2017).

A revisão integrativa permite que o leitor reconheça os profissionais que mais investigam determinado assunto, separar o achado científico de opiniões e ideias, além de descrever o conhecimento no seu estado atual, promovendo impacto sobre a prática clínica. Este método de pesquisa proporciona aos profissionais de saúde dados relevantes de um determinado assunto, em diferentes lugares e momentos, mantendo-os atualizados e facilitando as mudanças na prática clínica como consequência da pesquisa. Dessa forma, acredita-se que a revisão integrativa é uma ferramenta importante no processo de comunicação dos resultados de pesquisas, facilitando a utilização desses na prática clínica, uma vez que proporciona uma síntese do conhecimento já produzido e fornece subsídios para a melhoria da assistência à saúde (Mendes, Silveira, \& Galvão, 2008).

Na Figura 1, ilustrada abaixo está descrito no fluxograma as fases distintas da revisão integrativa da literatura segundo (Mendes, Silveira, \& Galvão 2008).

Figura 1. Fluxograma das fases distintas da revisão integrativa.

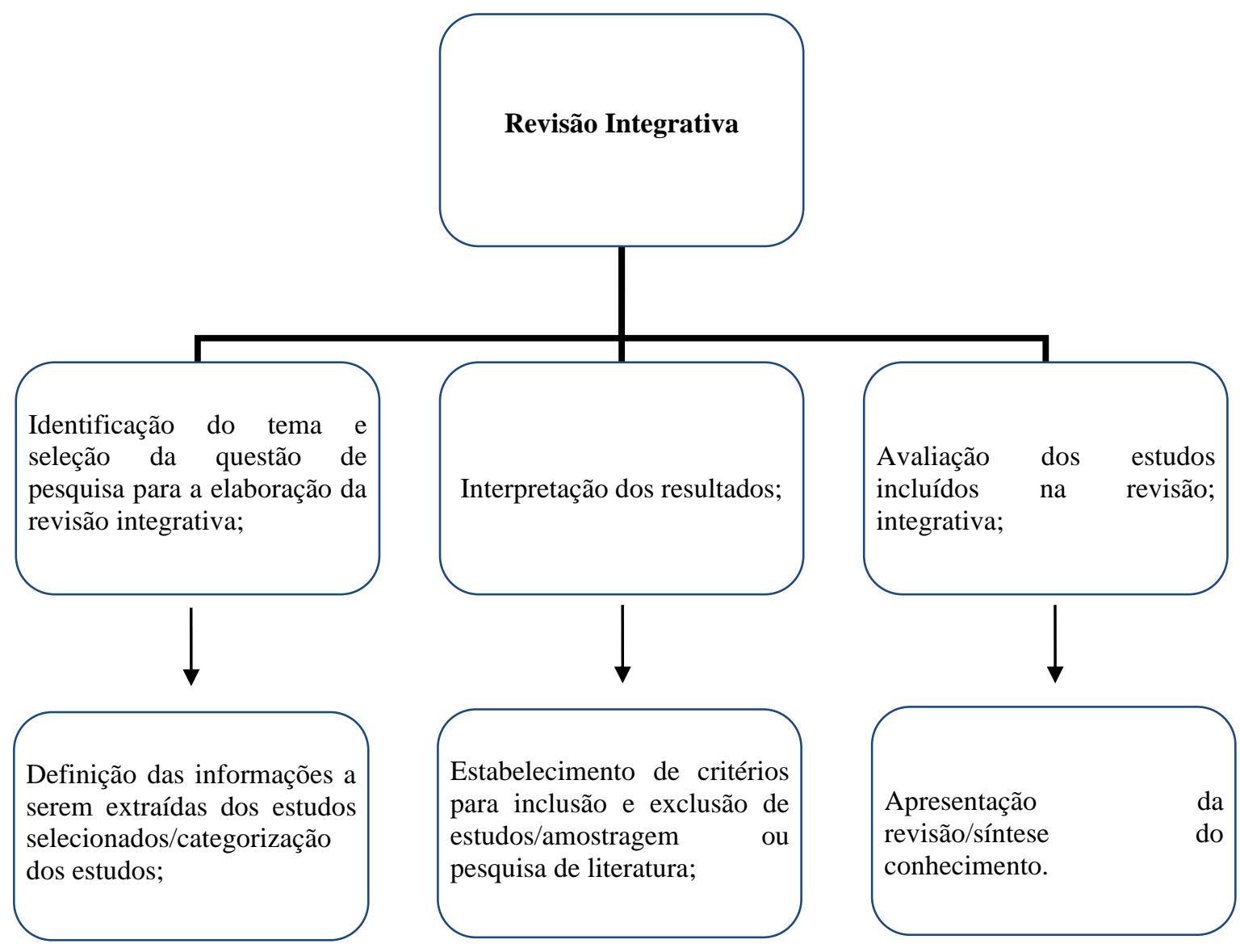

Fonte: Autores (2021). 
A revisão integrativa é um tipo de pesquisa que fornece informações mais amplas de maneira sistemática, ordenada e abrangente, sobre um assunto ou tema, com a finalidade de sintetizar resultados obtidos em pesquisa sobre temas ou questões. A definição das informações a serem extraídas dos estudos selecionados por categorização; avaliação dos estudos incluídos; interpretação dos resultados; e apresentação da revisão/síntese do conhecimento (Ercole, Melo, \& Alcoforado, 2015).

Estudo elaborado com abordagem qualitativa tornando-se importante a interpretação por parte do pesquisador com suas opiniões sobre o fenômeno em estudo. Neste tipo de pesquisa destacam-se algumas características como: a pesquisa qualitativa, em geral, ocorre no ambiente natural com coleta direta de dados e o pesquisador é o principal instrumento; os dados coletados são preferencialmente descritivos; a preocupação do processo é predominante em relação à do produto; a análise de dados e informações tende a seguir um processo indutivo (Pereira, Shitsuka, Parreira, \& Shitsuka, 2018).

A pesquisa qualitativa envolve uma abordagem interpretativa do mundo, o que significa que seus pesquisadores estudam as coisas em seus cenários naturais, tentando entender os fenômenos em termos dos significados que as pessoas a eles conferem. A pesquisa qualitativa atribui importância fundamental aos depoimentos dos atores sociais envolvidos, aos discursos e aos significados transmitidos por eles. Nesse sentido, esse tipo de pesquisa preza pela descrição detalhada dos fenômenos e dos elementos que o envolvem (Augusto, Souza, Dellagnelo, \& Cario, 2014).

De acordo com Souza, Silva, e Carvalho (2010), a ser realizada nas seguintes etapas: 1- Elaboração da pergunta norteadora; 2- Busca nas bases de dados e amostragem; 3- Coleta de dados, 4- Análise crítica.

Para responder à questão norteadora do estudo: "Quais as contribuições da assistência de enfermagem no acolhimento de adolescentes com ideações suicidas"? Aplicou-se os descritores/palavras-chaves: "Cuidados de Enfermagem", "Suicídio", "Adolescente".

A busca efetuou-se, através da Plataforma da Biblioteca Virtual em Saúde - BVS, utilizando as bases de dados Literatura Latino-Americana e do Caribe em Ciências da Saúde (LILACS), Base de Dados de Enfermagem (BDENF), por meio da - Scientific Electronic Library Online (SCIELO). Aderindo-se através dos descritores/palavras chaves: "Cuidados de Enfermagem", "Suicídio", “Adolescente”, combinados com o operador booleano "AND”.

Os critérios de inclusão estabelecidos foram: artigos originais disponibilizados na íntegra, completos, que abrangessem a temática e na forma online, publicados nos idioma português, inglês e espanhol, publicações que respondiam a questão norteadora do estudo. Os critérios de exclusão estabelecidos na seleção foram: artigos incompletos, artigos duplicados, teses, dissertações, monografias, manuais, e publicações que não estavam de acordo com a questão norteadora do estudo. No início da pesquisa obteve-se 644 publicações, após a aplicação dos critérios de inclusão e exclusão totalizou-se parcialmente 383 artigos, depois de uma leitura mais precisa aderiu-se um total final de 21 publicações de acordo para serem trabalhadas na elaboração do referido estudo.

O fluxograma representado abaixo, caracteriza a estratégia de coleta de dados utilizada pelos autores, no sentido de detalhar as principais evidencias encontradas no estudo. 
Figura 2. Fluxograma Estratégia de Busca - Bases de Dados, Teresina-PI, Brasil, 2021.

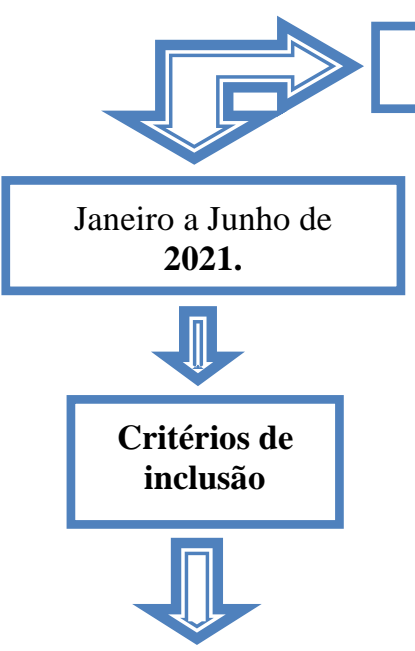

Artigos originais disponibilizados na íntegra, completos, que abrangessem a temática e na forma online, publicados nos idioma português, inglês e espanhol, publicações que respondiam a questão norteadora do estudo.

Estratégia de Busca Revisão Integrativa

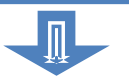

\section{Critérios de exclusão}

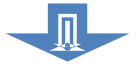

Artigos incompletos, artigos duplicados, teses, dissertações, monografias, manuais, e publicações que não estavam de acordo com a questão norteadora do estudo

.

\section{Amostra final}
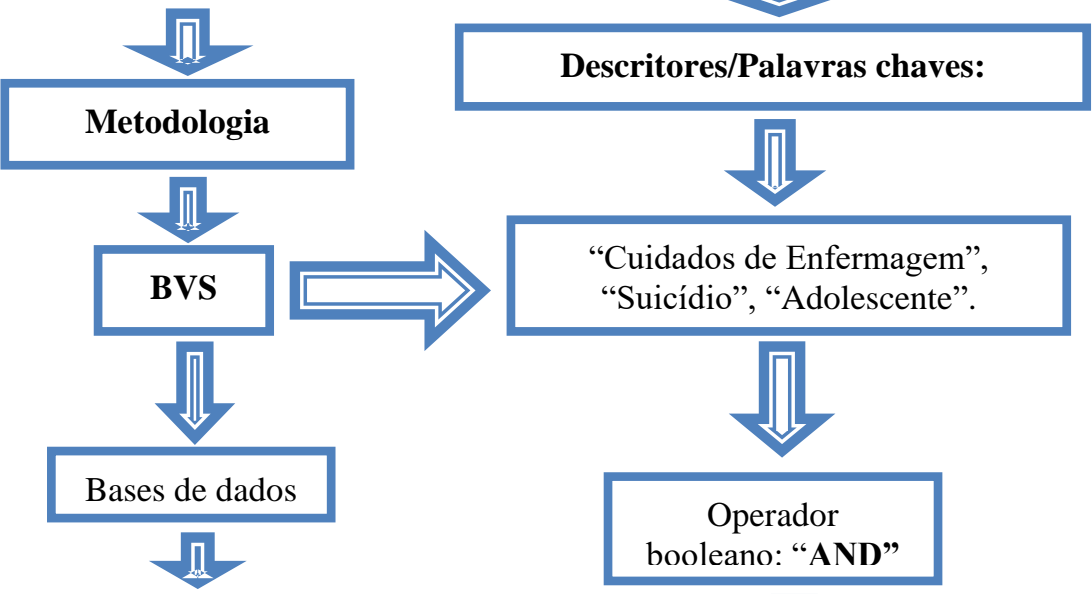

Operador booleano: "AND"
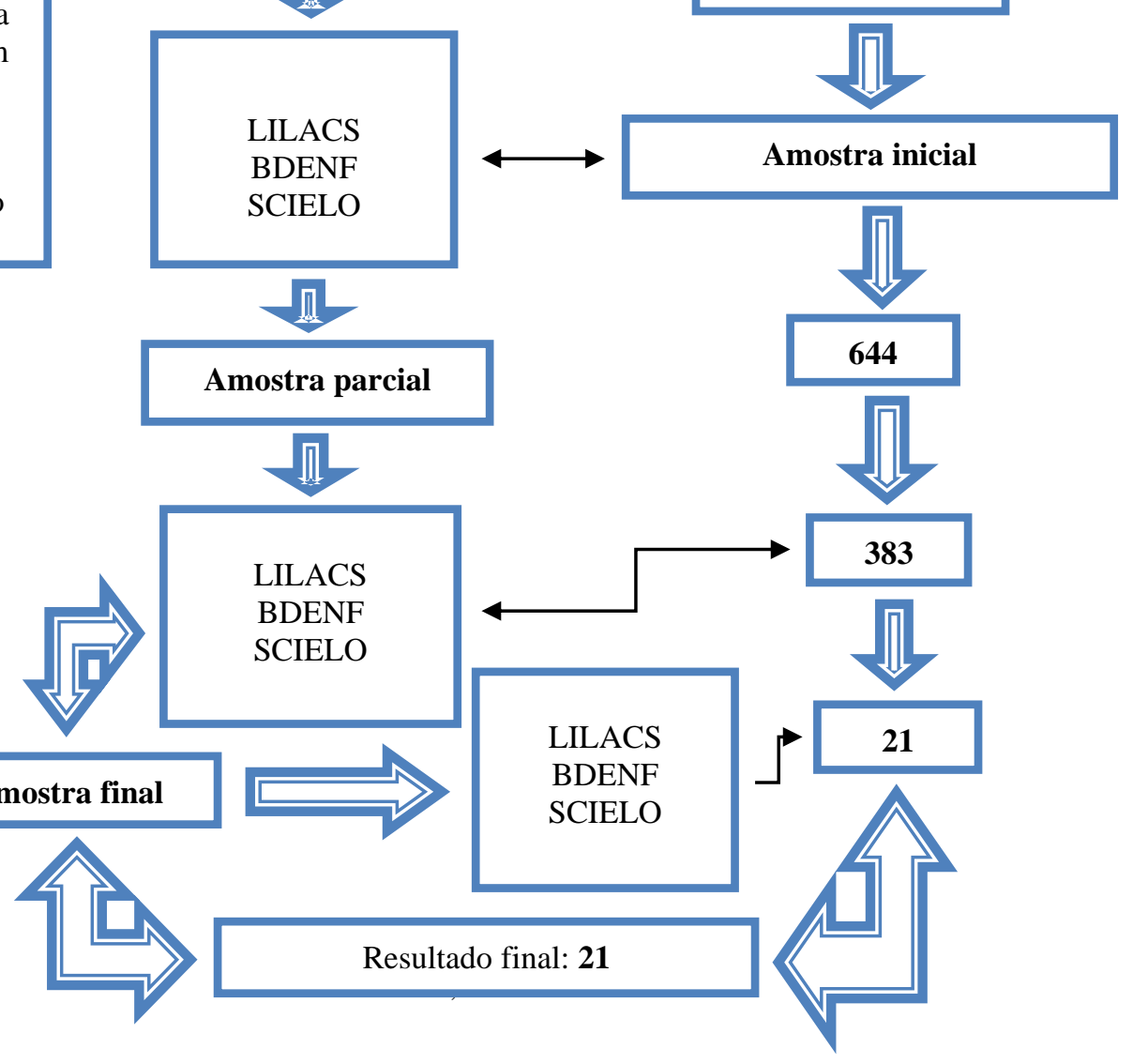

Fonte: Autores (2021).

No Fluxograma 2, estão expostos a estratégia de busca, bases de dados, período de realização do estudo, critérios de inclusão e exclusão, amostra inicial, parcial e final, de acordo com a quantidade de artigos que irão compor os resultados do estudo.

O presente estudo assegura os aspectos éticos, garantindo a autoria dos artigos pesquisados, utilizando para as citações e referências dos autores as normas APA. Os preceitos éticos estabelecidos no que se refere a zelar pela legitimidade das informações, privacidade e sigilo das informações, quando necessárias, tornando os resultados desta pesquisa públicos. Os pesquisadores buscaram a legitimidade e fidelidade nas citações dos autores seja nas citações diretas ou parafraseadas no estudo. 


\section{Resultados e Discussão}

Diante dos resultados obtidos no estudo por meio da estratégia de busca, os autores delinearam variáveis para melhor descrever as evidências encontradas na pesquisa. O quadro a seguir caracteriza os artigos com base nas variáveis propostas: número do artigo, base de dados, periódico, autor e ano de publicação, tipo de estudo, título, objetivo, resultados em evidências e conclusões importantes.

Quadro 1. Caracterização dos artigos selecionados para o estudo.

\begin{tabular}{|c|c|c|c|c|c|c|c|}
\hline $\mathbf{N}$ & $\begin{array}{l}\text { Base de } \\
\text { Dados }\end{array}$ & Periódico & $\begin{array}{l}\text { Autor e } \\
\text { Ano }\end{array}$ & $\begin{array}{l}\text { Tipo de } \\
\text { Estudo }\end{array}$ & Título & Objetivo & $\begin{array}{l}\text { Resultados em evidências e conclusões } \\
\text { importantes }\end{array}$ \\
\hline 1 & LILACS & $\begin{array}{l}\text { REME - } \\
\text { Revista } \\
\text { Mineira de } \\
\text { Enferma } \\
\text { gem. }\end{array}$ & $\begin{array}{l}\text { Pessoa et } \\
\text { al., } 2020 .\end{array}$ & $\begin{array}{c}\text { Estudo } \\
\text { descritivo e } \\
\text { exploratório, } \\
\text { com } \\
\text { abordagem } \\
\text { qualitativa. }\end{array}$ & $\begin{array}{l}\text { Assistência de } \\
\text { enfermagem na } \\
\text { atenção primária à } \\
\text { saúde r de } \\
\text { adolescentes com } \\
\text { ideações suicidas. }\end{array}$ & $\begin{array}{l}\text { Compreender como se } \\
\text { dá a assistência a } \\
\text { saúde prestada pelo } \\
\text { enfermeiros na } \\
\text { atenção primária aos } \\
\text { adolescentes com } \\
\text { ideações suicidas. }\end{array}$ & $\begin{array}{l}\text { Torna-se necessário que o enfermeiro da } \\
\text { atenção primária conheça o território e o } \\
\text { perfil de saúde dos adolescentes. Somado } \\
\text { a isso, a educação permanente deve } \\
\text { permitir a construção de novos saberes } \\
\text { necessários para abordar o tema na prática } \\
\text { do enfermeiro, bem como dos demais } \\
\text { profissionais que atuam na atenção } \\
\text { primária. Sugere-se que a área da saúde } \\
\text { mental seja fortalecida na formação do } \\
\text { enfermeiro, visto que o suicídio em jovens } \\
\text { vem aumentando e requer, portanto, } \\
\text { assistência integral da enfermagem aos } \\
\text { adolescentes. }\end{array}$ \\
\hline 2 & LILACS & $\begin{array}{l}\text { Rev. } \\
\text { Nufen: } \\
\text { Phenom. } \\
\text { Interd. }\end{array}$ & $\begin{array}{l}\text { Silva, } \\
\text { Soares, } \\
\text { Sousa, \& } \\
\text { Kusano, } \\
2019 .\end{array}$ & $\begin{array}{l}\text { Estudo } \\
\text { descritivo do } \\
\text { tipo relato de } \\
\text { experiência. }\end{array}$ & $\begin{array}{lr}\text { Promoção de } \\
\text { saúde mental para } \\
\text { adolescentes em } \\
\text { uma escola de } \\
\text { ensino médio. }\end{array}$ & $\begin{array}{l}\text { Relatar a experiência } \\
\text { de acadêmicos de } \\
\text { Enfermagem do UDF } \\
\text { Centro Universitário } \\
\text { sobre prática de } \\
\text { atividades com } \\
\text { estudantes de ensino } \\
\text { médio envolvendo } \\
\text { relações interpessoais, } \\
\text { bullying e suicídio. }\end{array}$ & $\begin{array}{l}\text { As atividades desenvolvidas propuseram } \\
\text { criar um ambiente mais aberto a } \\
\text { discussões e diminuir as agressões } \\
\text { causadas pelo bullying e melhorar o } \\
\text { convívio dos escolares. Promover } \\
\text { educação em saúde com intuito prevenir } \\
\text { todos os sintomas negativos que } \\
\text { pudessem contribuir para uma possível } \\
\text { ideação suicida e até mesmo a } \\
\text { consumação do suicídio de fato, uma vez } \\
\text { que aqueles que participaram das } \\
\text { atividades, conseguiram expor seus } \\
\text { sentimentos pessoais ou debater sobre os } \\
\text { sentimentos que geram aflição. }\end{array}$ \\
\hline 3 & BDENF & $\begin{array}{l}\text { Esc Anna } \\
\text { Nery. }\end{array}$ & $\begin{array}{l}\text { Buriola, } \\
\text { Arnauts, } \\
\text { Decesaro } \\
\quad, \\
\text { Oliveira, } \\
\quad \& \\
\text { Marcon, } \\
2011 .\end{array}$ & $\begin{array}{c}\text { Estudo } \\
\text { qualitativo. }\end{array}$ & $\begin{array}{lr}\text { Assistência } & \text { de } \\
\text { enfermagem } & \text { às } \\
\text { famílias } & \text { de } \\
\text { indivíduos que } & \text { tentaram suicídio. }\end{array}$ & \begin{tabular}{lr}
\multicolumn{2}{l}{ Conhecer a assistência } \\
de & enfermagem \\
oferecida & aos \\
familiares & de \\
indivíduos & que \\
tentaram & suicídio, \\
durante o atendimento \\
inicial da ocorrência.
\end{tabular} & $\begin{array}{l}\text { O estudo apresentou as ações dos } \\
\text { enfermeiros junto aos familiares de } \\
\text { pessoas que tentaram suicídio. Constatou- } \\
\text { se que estes profissionais abordam a } \\
\text { família basicamente para a busca de } \\
\text { informações referentes à tentativa de } \\
\text { suicídio, mas há os que não abordam a } \\
\text { família de forma alguma. }\end{array}$ \\
\hline 4 & SCIELO & $\begin{array}{l}\text { REFACS } \\
\text { (online). }\end{array}$ & $\begin{array}{l}\text { Schlichti } \\
\text { ng, \& } \\
\text { Moraes, } \\
2018 .\end{array}$ & $\begin{array}{c}\text { Estudo } \\
\text { qualitativo. }\end{array}$ & $\begin{array}{lr}\text { Mortalidade } & \text { por } \\
\text { suicídio } & \text { na } \\
\text { adolescência. } & \end{array}$ & 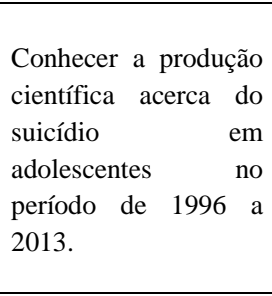 & $\begin{array}{l}\text { Os suicídios entre adolescentes crescem } \\
\text { de maneira importante tornando-se um } \\
\text { grande desafio para a saúde pública. Sua } \\
\text { relevância caracteriza-se por ser um } \\
\text { comportamento decisivo e, irreversível } \\
\text { quando consumado. Considerando a } \\
\text { premissa de que o adolescente em estado } \\
\text { de suicídio ofereça pistas, infere-se que a } \\
\text { o mesmo possa ser evitado. }\end{array}$ \\
\hline 5 & SCIELO & $\begin{array}{l}\text { Revista } \\
\text { Eletrônica } \\
\text { Acervo } \\
\text { Saúde / } \\
\text { Electronic } \\
\text { Journal } \\
\text { Collection } \\
\text { Health. }\end{array}$ & $\begin{array}{l}\text { Silva, } \\
\text { Vecchia, } \\
\text { Ramos, } \\
\& \text { Costa, } \\
2020 .\end{array}$ & $\begin{array}{l}\text { Estudo } \\
\text { qualitativo. }\end{array}$ & $\begin{array}{lr}\text { Profissionais } & \text { de } \\
\text { enfermagem } & \text { de } \\
\text { um serviço } & \text { de } \\
\text { urgência } & \mathrm{e} \\
\text { emergência frente } \\
\text { ao suicídio na } \\
\text { adolescência. }\end{array}$ & $\begin{array}{l}\text { Compreender como os } \\
\text { profissionais de } \\
\text { enfermagem de um } \\
\text { serviço de urgência e } \\
\text { emergência percebem } \\
\text { o suicídio na } \\
\text { adolescência. }\end{array}$ & $\begin{array}{l}\text { A enfermagem reconhece o suicídio na } \\
\text { adolescência como um problema atual e } \\
\text { emergente. Correlacionam-no com } \\
\text { características próprias da adolescência, } \\
\text { mas também compreendem que fatores } \\
\text { sociais e familiares influenciam na } \\
\text { conduta suicida. Percebe-se, portanto, a } \\
\text { necessidade de educação permanente com } \\
\text { profissionais que atuam diretamente com } \\
\text { estas emergências. }\end{array}$ \\
\hline 6 & SCIELO & $\begin{array}{l}\text { Revista } \\
\text { Eletrônica } \\
\text { Saúde }\end{array}$ & $\begin{array}{l}\text { Façanha, } \\
\text { Erse, } \\
\text { Simões, }\end{array}$ & $\begin{array}{c}\text { Estudo } \\
\text { descritivo - }\end{array}$ & $\begin{array}{lr}\text { Prevenção } & \text { do } \\
\text { suicídio } & \text { em } \\
\text { adolescentes: } & \text { pro - }\end{array}$ & $\begin{array}{l}\text { Analisar as evidências } \\
\text { científicas sobre à } \\
\text { prevenção do suicídio }\end{array}$ & $\begin{array}{l}\text { Ao desenvolver esforços para } \\
\text { implementar estratégias de prevenção do } \\
\text { suicídio em adolescentes, embora somente } \\
\text { alguns fatores de risco, haverá }\end{array}$ \\
\hline
\end{tabular}




\begin{tabular}{|c|c|c|c|c|c|c|c|}
\hline & & $\begin{array}{l}\text { Mental } \\
\text { Álcool e } \\
\text { Drogas. }\end{array}$ & $\begin{array}{l}\text { Amélia, } \\
\& \text { Santos, } \\
2010 .\end{array}$ & correlacional. & $\begin{array}{l}\text { grama de } \\
\text { intervenção belie - } \\
\text { ve. }\end{array}$ & em adolescentes. & $\begin{array}{l}\text { contribuição para a identificação precoce } \\
\text { de situações problema e para melhorar o } \\
\text { acesso aos cuidados de saúde mental. }\end{array}$ \\
\hline 7 & SCIELO & $\begin{array}{l}\text { Ciência \& } \\
\text { Saúde } \\
\text { Coletiva. }\end{array}$ & $\begin{array}{c}\text { Abasse, } \\
\text { Oliveira, } \\
\text { Silva, \& } \\
\text { Souza, } \\
2009 .\end{array}$ & $\begin{array}{l}\text { Análise } \\
\text { epidemiológi - } \\
\text { ca descritiva. }\end{array}$ & $\begin{array}{l}\text { Análise epidemi - } \\
\text { lógica da } \\
\text { morbimortalidade } \\
\text { por suicídio entre } \\
\text { adolescentes em } \\
\text { Minas Gerais, } \\
\text { Brasil. }\end{array}$ & $\begin{array}{l}\text { Realizar análise } \\
\text { epidemiológica da } \\
\text { morbimortalidade por } \\
\text { suicídio na faixa } \\
\text { etária de } 10-19 \text { anos } \\
\text { de residentes em } \\
\text { Minas Gerais. }\end{array}$ & $\begin{array}{l}\text { A morte dos jovens por causas violentas, } \\
\text { entre elas, o suicídio, é um dos problemas } \\
\text { atuais no mundo e também no Brasil. O } \\
\text { suicídio é um fenômeno que sofre a } \\
\text { interferência de fatores individuais, } \\
\text { ambientais, sociais. Seja na forma de } \\
\text { tentativa ou do ato consumado, expressa } \\
\text { uma dor emocional que o sujeito } \\
\text { considera ser interminável, intolerável e } \\
\text { com a qual acredita não ter capacidade de } \\
\text { lidar. }\end{array}$ \\
\hline 8 & SCIELO & $\begin{array}{l}\text { Epidemiol. } \\
\text { Serv. } \\
\text { Saude. }\end{array}$ & $\begin{array}{l}\text { Fernande } \\
\text { s et al., } \\
2020 .\end{array}$ & $\begin{array}{l}\text { Estudo } \\
\text { ecológico de } \\
\text { séries } \\
\text { temporais com } \\
\text { dados do } \\
\text { (SIM). }\end{array}$ & $\begin{array}{l}\text { Tendência } \quad \text { de } \\
\text { suicídio } \\
\text { adolescentes } \\
\text { brasileiros entre } \\
\text { 1997 e 2016. }\end{array}$ & 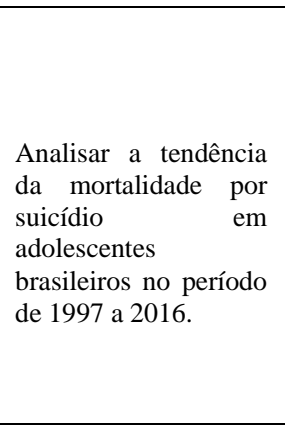 & $\begin{array}{l}\text { Os achados do estudo demonstram a } \\
\text { relevância da temática enquanto problema } \\
\text { de Saúde Pública e permitem uma melhor } \\
\text { compreensão epidemiológica do suicídio } \\
\text { em adolescentes. Esse entendimento é } \\
\text { necessário para a elaboração de } \\
\text { estratégias de intervenção que visem à } \\
\text { divulgação dos riscos, a criação de } \\
\text { programas de prevenção e impacto } \\
\text { relacionados ao suicídio e o tratamento } \\
\text { oportuno de transtornos mentais e/ou } \\
\text { incapacidades decorrentes de tentativas } \\
\text { anteriores. }\end{array}$ \\
\hline 9 & SCIELO & $\begin{array}{l}\text { Pensando } \\
\text { Famílias. }\end{array}$ & $\begin{array}{l}\text { Magnani, } \\
\& \text { Staudt, } \\
2018\end{array}$ & $\begin{array}{c}\text { Estudo } \\
\text { exploratório. }\end{array}$ & 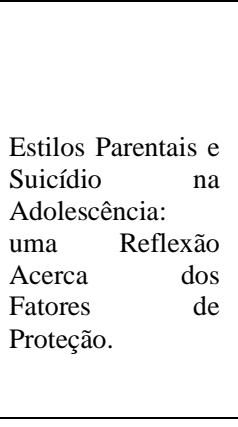 & $\begin{array}{l}\text { Compreender os } \\
\text { estilos parentais e de } \\
\text { que modo as relações } \\
\text { entre pais e filhos são } \\
\text { estabelecidas, afim de } \\
\text { prevenir } \\
\text { fenômeno. }\end{array}$ & $\begin{array}{l}\text { A enfermagem pode desempenhar papel } \\
\text { fundamental ao atuar na prevenção de } \\
\text { suicídio em adolescentes. Atuando no } \\
\text { desenvolvimento de competências e } \\
\text { habilidades parentais, oferecendo suporte } \\
\text { emocional aos cuidadores e aos jovens, } \\
\text { além de trabalhar a dinâmica das relações } \\
\text { parentais e familiares. É necessário ainda } \\
\text { sensibilizar os pais quanto aos fatores de } \\
\text { risco, orientá-los sobre a influência } \\
\text { parental e engajá-los nos cuidados e no } \\
\text { tratamento, quando necessário, de seus } \\
\text { filhos. }\end{array}$ \\
\hline $\begin{array}{l}1 \\
0\end{array}$ & SCIELO & $\begin{array}{l}\text { Revista } \\
\text { Enfermage } \\
\mathrm{m} \\
\text { Contempo - } \\
\text { rânea. }\end{array}$ & $\begin{array}{l}\text { Oliveira } \\
\text { et al., } \\
2016 .\end{array}$ & $\begin{array}{c}\text { Estudo } \\
\text { transversal, } \\
\text { descritivo - } \\
\text { exploratório. }\end{array}$ & $\begin{array}{lr}\text { Aspectos epide } & - \\
\text { miológicos } & \text { e } \\
\text { cuidado } & \text { de } \\
\text { enfermagem } & \text { na } \\
\text { tentativa } & \text { de } \\
\text { suicídio. } & \end{array}$ & 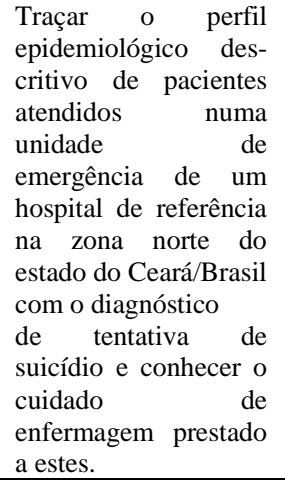 & $\begin{array}{l}\text { Neste contexto, é fundamental a aplicação } \\
\text { de práticas desenvolvidas especificamente } \\
\text { para este público, pois a pessoa que tenta } \\
\text { suicídio, ao receber o primeiro } \\
\text { atendimento em uma unidade de saúde, } \\
\text { encontra-se em um momento de extrema } \\
\text { vulnerabilidade. Além disso, o } \\
\text { investimento em uma formação } \\
\text { direcionada à saúde mental como aspecto } \\
\text { transversal ao cuidado pode ser, a longo } \\
\text { prazo, uma alternativa para revalorizar e } \\
\text { ressignificar a assistência. }\end{array}$ \\
\hline $\begin{array}{l}1 \\
1\end{array}$ & SCIELO & $\begin{array}{c}\text { Revista } \\
\text { Portuguesa } \\
\text { de } \\
\text { Enfermage } \\
\text { m de Saúde } \\
\text { Mental. }\end{array}$ & $\begin{array}{l}\text { Simões, } \\
\text { Santos, \& } \\
\text { Martinho } \\
\text {,2020. }\end{array}$ & $\begin{array}{l}\text { Estudo de } \\
\text { escopo. }\end{array}$ & $\begin{array}{l}\text { As representações } \\
\text { sociais do suicídio } \\
\text { em adolescentes. }\end{array}$ & $\begin{array}{lr}\text { Mapear } & \text { as } \\
\text { representações } & \text { sociais } \\
\text { do suicídio em } \\
\text { adolescentes. }\end{array}$ & $\begin{array}{l}\text { As representações sociais do suicídio em } \\
\text { adolescentes diferem entre estudos, } \\
\text { verificando-se escassez de estudos } \\
\text { internacionais e a utilização de diferentes } \\
\text { metodologias e diferentes instrumentos de } \\
\text { avaliação não sendo por isso possível a } \\
\text { comparação de resultados. Reforça-se a } \\
\text { necessidade de promover investigação } \\
\text { nesta área e contribuir para a adaptação de } \\
\text { estratégias de prevenção do suicídio. }\end{array}$ \\
\hline $\begin{array}{l}1 \\
2\end{array}$ & SCIELO & $\begin{array}{l}\text { RSP - } \\
\text { Revista de } \\
\text { Saúde } \\
\text { Pública. } \\
\end{array}$ & $\begin{array}{c}\text { Sousa et } \\
\text { al., } 2020 .\end{array}$ & $\begin{array}{c}\text { Estudo } \\
\text { transversal. }\end{array}$ & $\begin{array}{l}\text { Ideação suicida e } \\
\text { fatores associados } \\
\text { entre escolares } \\
\text { adolescentes. }\end{array}$ & $\begin{array}{l}\text { Analisar a prevalência } \\
\text { de ideação suicida e } \\
\text { fatores associados em } \\
\text { adolescentes escola - }\end{array}$ & $\begin{array}{l}\text { Um dos fatores relacionados à maior } \\
\text { prevalência da ideação suicida entre } \\
\text { garotas pode estar ligado ao fato de elas } \\
\text { entrarem mais cedo na fase da puberdade, } \\
\text { experimentando antes dos garotos as } \\
\text { mudanças físicas e pressões próprias do } \\
\text { período, especialmente as relacionadas ao } \\
\text { que se espera de seu comportamento na } \\
\text { sociedade e às repressões familiares que } \\
\text { elas sofrem. Ademais, apresentam }\end{array}$ \\
\hline
\end{tabular}




\begin{tabular}{|c|c|c|c|c|c|c|c|}
\hline & & & & & & res. & $\begin{array}{l}\text { problemas psicológicos mais recorrentes, } \\
\text { como a depressão, perturbação de humor, } \\
\text { ansiedade e introspecção, fatores que } \\
\text { estão fortemente relacionados com o } \\
\text { surgimento da ideação suicida. }\end{array}$ \\
\hline $\begin{array}{l}1 \\
3\end{array}$ & SCIELO & $\begin{array}{c}\text { Researchga } \\
\text { te. } \\
\text { net. }\end{array}$ & $\begin{array}{l}\text { Lopes, } \\
\text { Tavares, } \\
\& \\
\text { Marques, } \\
2015 .\end{array}$ & $\begin{array}{c}\text { Estudo } \\
\text { qualitativo. }\end{array}$ & $\begin{array}{l}\text { Tentativa de } \\
\text { Suicídio no } \\
\text { Adolescente: } \\
\text { Relação Enfer - } \\
\text { meiro-Adolescent } \\
\text { e no serviço de } \\
\text { urgência. }\end{array}$ & 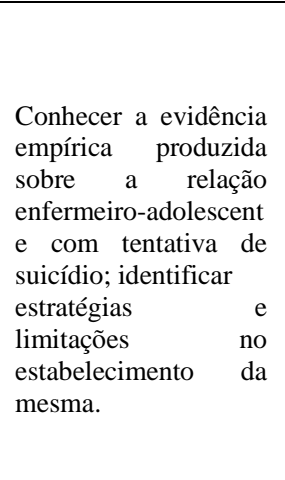 & $\begin{array}{l}\text { A procura dos serviços de urgência e de } \\
\text { ajuda especializada pelos adolescentes } \\
\text { com tentativa de suicídio deve ser } \\
\text { interpretada pelos profissionais de saúde } \\
\text { como um "grito de dor", a procura de } \\
\text { ajuda, de uma luz no fundo do túnel. } \\
\text { Constata-se ser fundamental o enfermeiro } \\
\text { procurar estabelecer uma relação empática } \\
\text { com o adolescente, ser genuíno e } \\
\text { atencioso sem juízos sobre o ato } \\
\text { cometido, escutando o adolescente, } \\
\text { promovendo uma comunicação eficaz e } \\
\text { criando condições para este expressar os } \\
\text { seus sentimentos e poder iniciar o } \\
\text { processo de recuperação. }\end{array}$ \\
\hline $\begin{array}{l}1 \\
4\end{array}$ & SCIELO & $\begin{array}{l}\text { ID Online } \\
\text { Revista de } \\
\text { Psicologia. }\end{array}$ & $\begin{array}{l}\text { Gonçalve } \\
\quad \text { \& } \\
\text { Randema } \\
\text { rk, 2014. }\end{array}$ & $\begin{array}{l}\text { Estudo } \\
\text { descritivo com } \\
\text { abordagem } \\
\text { qualitativo. }\end{array}$ & $\begin{array}{l}\text { Suicídio na } \\
\text { Adolescência: } \\
\text { representações dos } \\
\text { pacientes e suas } \\
\text { Famílias. }\end{array}$ & $\begin{array}{lr}\text { Apreender } & \text { as } \\
\text { representações dos } \\
\text { adolescentes acerca da } \\
\text { morte e do morrer; } \\
\text { identificar quais os } \\
\text { determinantes socio- } \\
\text { culturais do intento } \\
\text { suicida } & \text { em } \\
\text { adolescentes. }\end{array}$ & $\begin{array}{l}\text { O estudo possibilitou a compreensão dos } \\
\text { determinantes socioculturais e da } \\
\text { dinâmica afetivo relacional na produção } \\
\text { do desejo suicida em adolescentes, } \\
\text { fornecendo subsídios para ações } \\
\text { preventivas a serem efetivadas de forma } \\
\text { integrada, envolvendo outros } \\
\text { protagonistas, contexto assistenciais da } \\
\text { rede de apoio, dentre eles, as famílias, o } \\
\text { ambiente hospitalar, o poder público e as } \\
\text { pessoas da comunidade a fim de que } \\
\text { possam identificar e minimizar o } \\
\text { potencial de risco de recidiva para o } \\
\text { suicídio e promover a reabilitação } \\
\text { psicossocial. }\end{array}$ \\
\hline $\begin{array}{l}1 \\
5\end{array}$ & SCIELO & $\begin{array}{c}\text { Revista } \\
\text { Cuidarte. }\end{array}$ & $\begin{array}{c}\text { Sousa et } \\
\text { al., } 2019 .\end{array}$ & $\begin{array}{c}\text { Estudo } \\
\text { descritivo e } \\
\text { exploratório, } \\
\text { com } \\
\text { abordagem } \\
\text { qualitativo. }\end{array}$ & $\begin{array}{lr}\text { Prevenção } & \text { ao } \\
\text { suicídio } & \text { na } \\
\text { atenção } & \text { básica: } \\
\text { concepção } & \text { de } \\
\text { enfermeiros. } & \end{array}$ & $\begin{array}{l}\text { Descrever a opinião } \\
\text { de Enfermeiros da } \\
\text { Atenção Básica acerca } \\
\text { da prevenção do } \\
\text { suicídio à luz das } \\
\text { políticas públicas } \\
\text { vigentes no Brasil. }\end{array}$ & $\begin{array}{l}\text { Os enfermeiros sentem a necessidade de } \\
\text { capacitação e treinamento sobre a } \\
\text { temática para realização de estratégias a } \\
\text { serem desenvolvidas no ambiente de } \\
\text { trabalho. Contudo, vale ressaltar que tais } \\
\text { profissionais são habilitados para } \\
\text { desenvolver métodos de prevenção, } \\
\text { considerando-se os recursos existentes na } \\
\text { Atenção Básica e o que a Rede de } \\
\text { Atenção à saúde dispõe. O enfermeiro da } \\
\text { Atenção Básica possui habilidades, } \\
\text { estrutura e conhecimentos que são } \\
\text { capazes de ajudar no processo de } \\
\text { desenvolvimento de técnicas que possam } \\
\text { contribuir com a redução do número de } \\
\text { casos de suicídio. }\end{array}$ \\
\hline $\begin{array}{l}1 \\
6\end{array}$ & SCIELO & $\begin{array}{l}\text { Perspectiva } \\
\text { : Ciência e } \\
\text { Saúde. }\end{array}$ & $\begin{array}{l}\text { Cardoso, } \\
\quad \& \\
\text { Cecconel } \\
\text { lo, } 2019 .\end{array}$ & $\begin{array}{c}\text { Estudo } \\
\text { qualitativo. }\end{array}$ & $\begin{array}{l}\text { Fatores de risco e } \\
\text { proteção para o } \\
\text { suicídio } \\
\text { adolescência. }\end{array}$ & $\begin{array}{l}\text { É identificar os } \\
\text { fatores de risco para o } \\
\text { suicídio } r \text { na } \\
\text { adolescência, bem } \\
\text { como analisar os } \\
\text { fatores de proteção } \\
\text { para a prevenção } \\
\text { deste grave problema } \\
\text { de saúde. }\end{array}$ & $\begin{array}{l}\text { A adolescência é uma fase composta por } \\
\text { diversas mudanças e alterações físicas e } \\
\text { psicológicas. Frente a estas mudanças, o } \\
\text { jovem está em processo de construção de } \\
\text { sua identidade, iniciando suas primeiras } \\
\text { relações com o contexto social e } \\
\text { possibilitando essa inserção através de } \\
\text { suas experiências sociais vivenciadas, } \\
\text { podendo estar mais suscetível a se expor a } \\
\text { comportamentos de risco, prejudicando } \\
\text { em seu desenvolvimento social e } \\
\text { cognitivo. Destaca-se aqui a importância } \\
\text { da família como papel protetivo na } \\
\text { relação dos vínculos sociais adequados, de } \\
\text { proteção, cuidado e autonomia. }\end{array}$ \\
\hline $\begin{array}{l}1 \\
7\end{array}$ & SCIELO & $\begin{array}{l}\text { Revista } \\
\text { Uningá. }\end{array}$ & $\begin{array}{l}\text { Silva, } \\
\text { Silva, } \\
\text { Lima, } \\
\text { Costa, \& } \\
\text { Costa, } \\
2019 .\end{array}$ & $\begin{array}{c}\text { Estudo } \\
\text { descritivo do } \\
\text { tipo } \\
\text { transversal } \\
\text { com } \\
\text { abordagem } \\
\text { quantitativa. }\end{array}$ & $\begin{array}{lr}\text { Internações } & \text { por } \\
\text { tentativa } & \text { de } \\
\text { suicídio } & \text { entre } \\
\text { adolescentes } & \text { e } \\
\text { jovens no acre de } \\
2008 \text { a 2018. }\end{array}$ & $\begin{array}{l}\text { Quantificar os casos } \\
\text { de internações por } \\
\text { tentativa de suicídio } \\
\text { entre adolescentes e } \\
\text { jovens no Acre de } \\
2008 \text { a } 2018 \text {. }\end{array}$ & $\begin{array}{l}\text { Recomenda-se que haja uma melhoria na } \\
\text { qualificação dos profissionais que atuam } \\
\text { frente a esse público alvo, no sentido de } \\
\text { identificar previamente possíveis casos, } \\
\text { desencadeando uma melhor assistência e } \\
\text { acolhimento, proporcionando dessa forma } \\
\text { a prestação dos cuidados necessários e } \\
\text { medidas terapêuticas, além da } \\
\text { sensibilização dos profissionais para que o } \\
\text { problema não seja mais visto como algo }\end{array}$ \\
\hline
\end{tabular}


Research, Society and Development, v. 10, n. 9, e6510917740, 2021

(CC BY 4.0) | ISSN 2525-3409 | DOI: http://dx.doi.org/10.33448/rsd-v10i9.17740

\begin{tabular}{|c|c|c|c|c|c|c|c|}
\hline & & & & & & & banal. \\
\hline $\begin{array}{l}1 \\
8\end{array}$ & SCIELO & $\begin{array}{l}\text { Cadernos } \\
\text { de } \\
\text { Psicologia } \\
\text { - CESJF. }\end{array}$ & $\begin{array}{l}\text { Morais, } \\
\text { \& Lima, } \\
2019 .\end{array}$ & $\begin{array}{c}\text { Estudo } \\
\text { qualitativo. }\end{array}$ & $\begin{array}{lr}\text { Suicídio } & \text { na } \\
\text { adolescência: } & \text { um } \\
\text { descompasso } & \text { na } \\
\text { vida. } & \end{array}$ & $\begin{array}{l}\text { Compreender a } \\
\text { psicodinâmica do } \\
\text { sujeito que pratica o } \\
\text { ato autodestrutivo. }\end{array}$ & $\begin{array}{l}\text { A comunicação clara, aberta e criteriosa é } \\
\text { um fator que auxilia na disseminação de } \\
\text { orientações que contribuem na tarefa de } \\
\text { prevenção. Trazer as questões do suicídio } \\
\text { para o debate e encorajar a discussão do } \\
\text { tema significam mais chances de afastar } \\
\text { tabus, preconceitos e estigmas. }\end{array}$ \\
\hline $\begin{array}{l}1 \\
9\end{array}$ & SCIELO & $\begin{array}{l}\text { Revista } \\
\text { JRG de } \\
\text { Estudos } \\
\text { Acadêmico } \\
\text { s. }\end{array}$ & $\begin{array}{c}\text { Marça, \& } \\
\text { Gonçalve } \\
\text { s, } 2020 .\end{array}$ & $\begin{array}{c}\text { Estudo } \\
\text { qualitativo. }\end{array}$ & $\begin{array}{l}\text { Estratégias de } \\
\text { intervenção do } \\
\text { enfermeiro diante } \\
\text { do comportamento } \\
\text { e tentativa de } \\
\text { autoextermínio. }\end{array}$ & $\begin{array}{lr}\text { Analisar } & \text { o } \\
\text { conhecimento } & \text { es } \\
\text { estratégias } & \text { de } \\
\text { intervenção } & \text { dos } \\
\text { enfermeiros prestados } \\
\text { aos usuários com } \\
\text { comportamento sui }- \\
\text { cida. }\end{array}$ & $\begin{array}{l}\text { As intervenções de enfermagem são } \\
\text { essenciais para a identificação dos } \\
\text { pacientes com risco ao suicídio, são o } \\
\text { acolhimento do paciente em local seguro, } \\
\text { a realização da anamnese e a classificação } \\
\text { de risco. São ações realizadas na atenção } \\
\text { primária que ajudam a minimizar o } \\
\text { comportamento suicida. }\end{array}$ \\
\hline $\begin{array}{l}2 \\
0\end{array}$ & SCIELO & $\begin{array}{l}\text { Rev. Eletr. } \\
\text { Enf. }\end{array}$ & $\begin{array}{l}\text { Hildebra } \\
\text { ndt, Zart, } \\
\text { \& Leite, } \\
2011 .\end{array}$ & $\begin{array}{c}\text { Estudo } \\
\text { descritivo. }\end{array}$ & $\begin{array}{ll}\text { A tentativa } & \text { de } \\
\text { suicídio } & \text { na } \\
\text { percepção } & \text { de } \\
\text { adolescentes. } & \end{array}$ & $\begin{array}{l}\text { Conhecer os métodos } \\
\text { utilizados pelos } \\
\text { adolescentes para } \\
\text { tentar suicídio e } \\
\text { analisar os motivos } \\
\text { que determinaram esta } \\
\text { ação. }\end{array}$ & $\begin{array}{l}\text { Os jovens tornam-se mais suscetíveis ao } \\
\text { ato suicida por apresentarem, com } \\
\text { frequência, ideações suicidas e, por vezes, } \\
\text { associarem o uso de substâncias } \\
\text { psicoativas. E, ainda, pela facilidade de } \\
\text { acesso a medicamentos psicotrópicos, } \\
\text { objetos cortantes e, especialmente, por } \\
\text { permanecerem sós nos momentos de } \\
\text { crises. }\end{array}$ \\
\hline $\begin{array}{l}2 \\
1\end{array}$ & SCIELO & $\begin{array}{l}\text { Revista } \\
\text { Inova } \\
\text { Saúde. }\end{array}$ & $\begin{array}{l}\text { Zanette, } \\
\text { Kern, } \\
\text { Losso, \& } \\
\text { Amboni, } \\
2020 .\end{array}$ & $\begin{array}{c}\text { Estudo } \\
\text { documental. }\end{array}$ & $\begin{array}{lr}\text { Tentativa } & \text { de } \\
\text { suicídio } & \text { na } \\
\text { adolescência:pers- } \\
\text { pectiva psicanali- } \\
\text { tica. }\end{array}$ & $\begin{array}{l}\text { Estudar a ocorrência } \\
\text { de tentativa de } \\
\text { suicídio frente à } \\
\text { vivência, por parte do } \\
\text { sujeito, de situações } \\
\text { traumáticas. }\end{array}$ & $\begin{array}{l}\text { Acredita-se ser indispensável ao } \\
\text { profissional de saúde mental saber "os } \\
\text { efeitos destrutivos e mortíferos de } \\
\text { experiências traumáticas que deixam o } \\
\text { sujeito preso à um tempo que não passa." } \\
\text { Cabe aos profissionais de saúde estarem } \\
\text { atentos a essas ocorrências que vêm } \\
\text { crescendo e mostrando a importância da } \\
\text { nossa disponibilidade para mobilizar } \\
\text { recursos técnicos e, essencialmente, } \\
\text { humanos no manejo com essa população } \\
\text { tão fragilizada. }\end{array}$ \\
\hline
\end{tabular}

Fonte: Autores (2021).

No Quadro 1, tem-se a apresentação dos artigos selecionados para o estudo conforme número do artigo, base de dados, periódico, autor e ano de publicação, tipo de estudo, título, objetivo, resultados em evidências e conclusões importantes, com a finalidade de facilitar o desenvolvimento da discussão. A partir do estudo dos artigos estabeleceram-se discussões relevantes para observações das produções científicas relacionadas à pesquisa.

No gráfico a seguir, estão expostos os periódicos e a quantidade de artigos encontrados na seleção da amostra final dos artigos que são trabalhados na elaboração do referido estudo. 
Gráfico 1. Distribuição dos artigos conforme periódico e quantidade e quantidade de artigos.

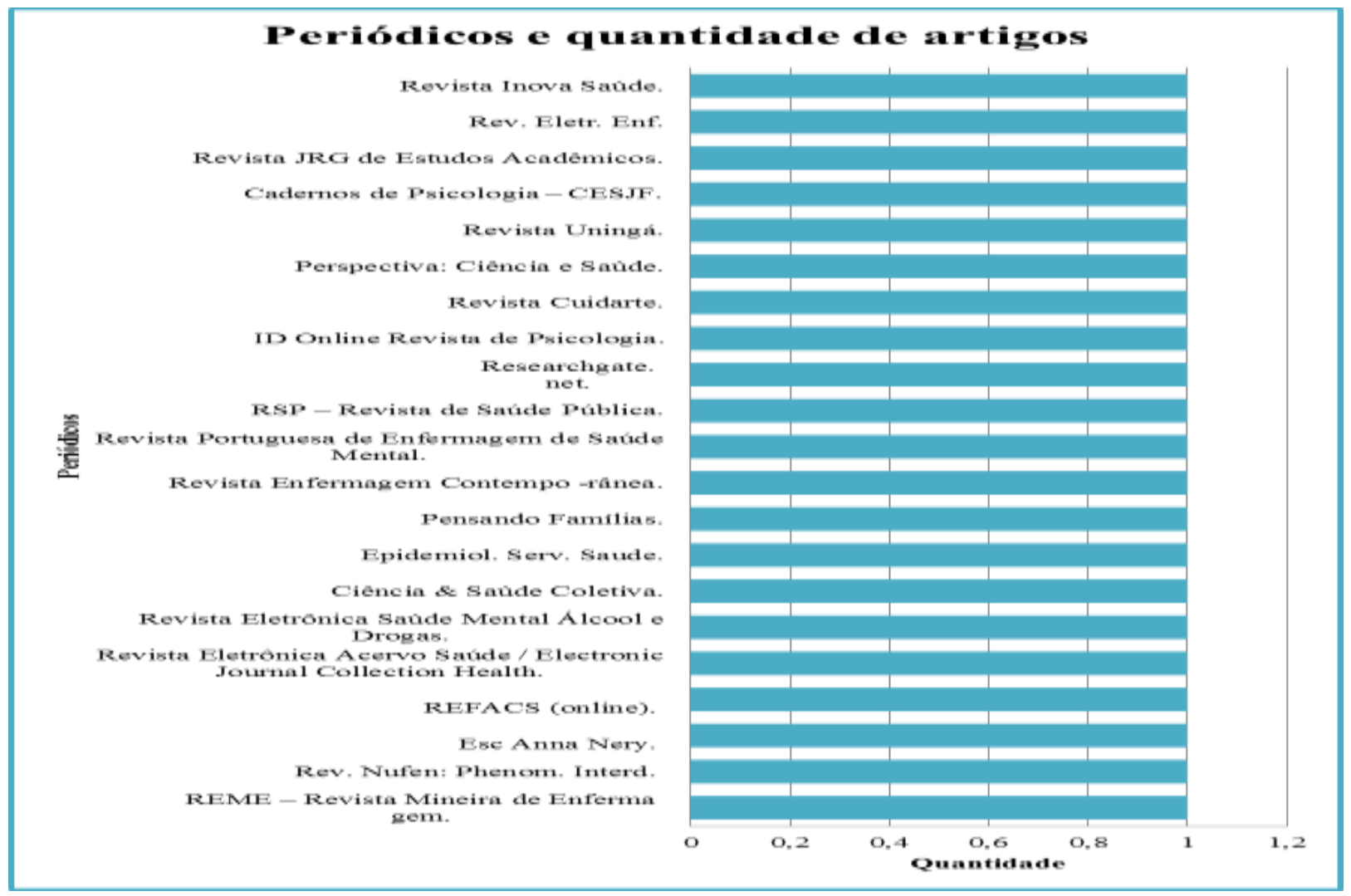

Fonte: Autores (2021).

Segundo o gráfico ilustrado acima, pode-se observar os periódicos e a quantidade de artigos que foram publicados de acordo com a amostra final do referido estudo. Dessa forma, verifica-se que na Revista Inova Saúde ocorreu (1) publicação, Revista Eletrônica de Enfermagem (1), Revista JRG de Estudos Acadêmicos (1), Cadernos de Psicologia - CESF (1), Revista Uninga (1), Perspectiva: Ciência e Saúde (1), Revista Cuidarte (1), ID Online Revista de Psicologia (1), Researchgate. Net (1), RSP - Revista de Saúde Pública (1), Revista Portuguesa de Enfermagem de Saúde Mental (1), Revista de Enfermagem Contemporânea (1) Pensando Famílias (1), Epidemiologia Serviço Saúde (1), Ciência e Saúde Coletiva (1), Revista Eletrônica Acervo Saúde / Electrônic Journal Collection Health (1), REFACS Online (1), Escola Anna Nery (1), Rev. Nufen: Phenom. Interd (1), REME - Revista Mineira de Enfermagem (1). Assim, totalizando 21 artigos para serem trabalhados na elaboração do presente estudo. 
Gráfico 2. Distribuição dos artigos conforme periódicos e porcentagem.

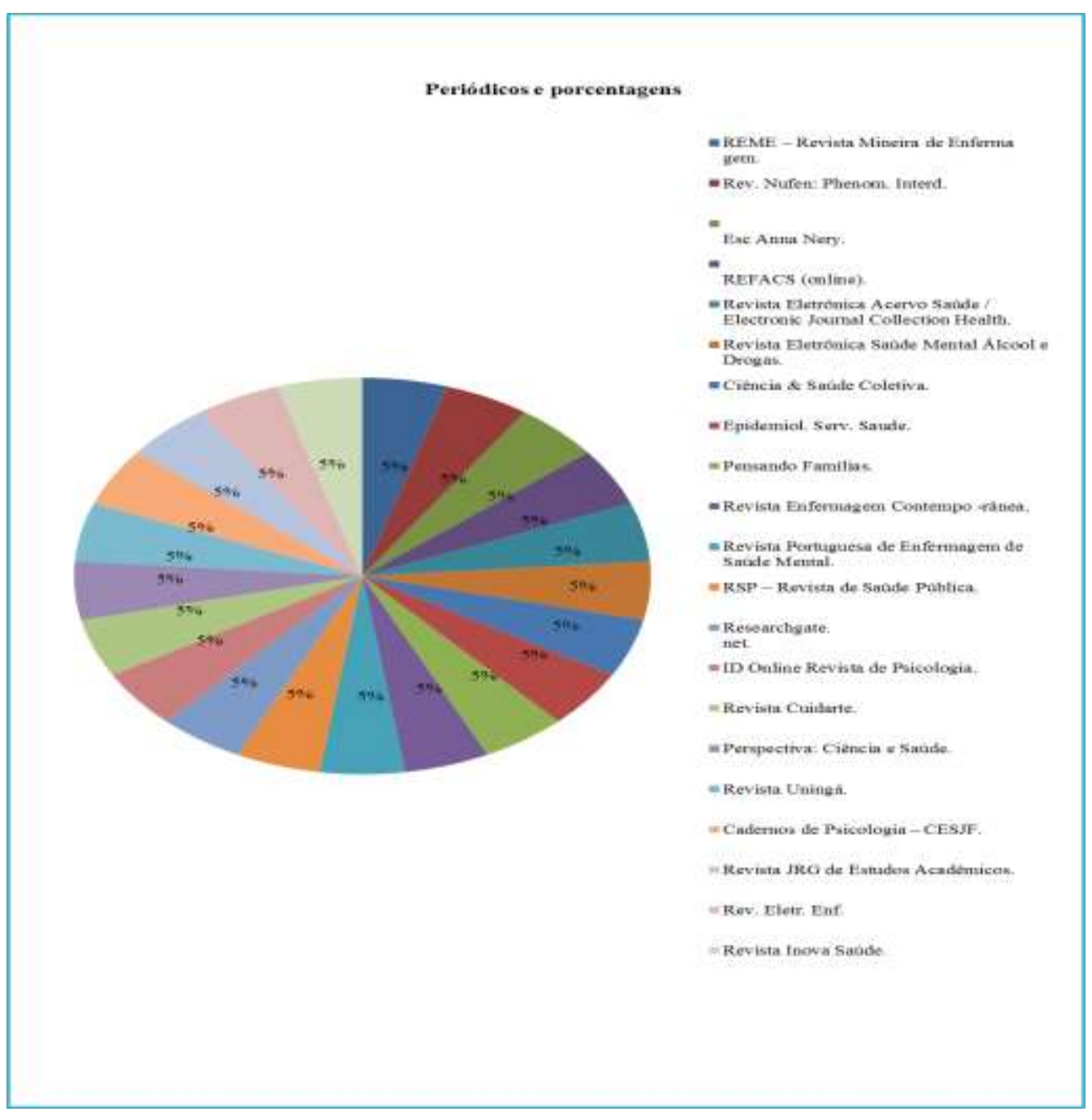

Fonte: Autores (2021).

De acordo, com o gráfico ilustrado acima, pode-se observar os periódicos e a porcentagem de artigos que foram publicados de acordo com a amostra final do referente estudo. Dessa forma, verifica-se que na Revista Inova Saúde ocorreu (5\%) publicação, Revista Eletrônica de Enfermagem (5\%), Revista JRG de Estudos Acadêmicos (5\%), Cadernos de Psicologia - CESF (5\%), Revista Uninga (5\%), Perspectiva: Ciência e Saúde (5\%), Revista Cuidarte (5\%), ID Online Revista de Psicologia (5\%), Researchgate. Net (5\%), RSP - Revista de Saúde Pública (5\%), Revista Portuguesa de Enfermagem de Saúde Mental (5\%), Revista de Enfermagem Contemporânea (5\%) Pensando Famílias (5\%), Epidemiologia Serviço Saúde (5\%), Ciência e Saúde Coletiva (5\%), Revista Eletrônica Acervo Saúde / Electrônic Journal Collection Health (5\%), REFACS Online (5\%), Escola Anna Nery (5\%), Rev. Nufen: Phenom. Interd (5\%), REME - Revista Mineira de Enfermagem (5\%). Assim, totalizando 21 artigos para serem trabalhados na elaboração do presente estudo. 
Gráfico 3. Distribuição dos artigos conforme os anos de publicação e quantidade.

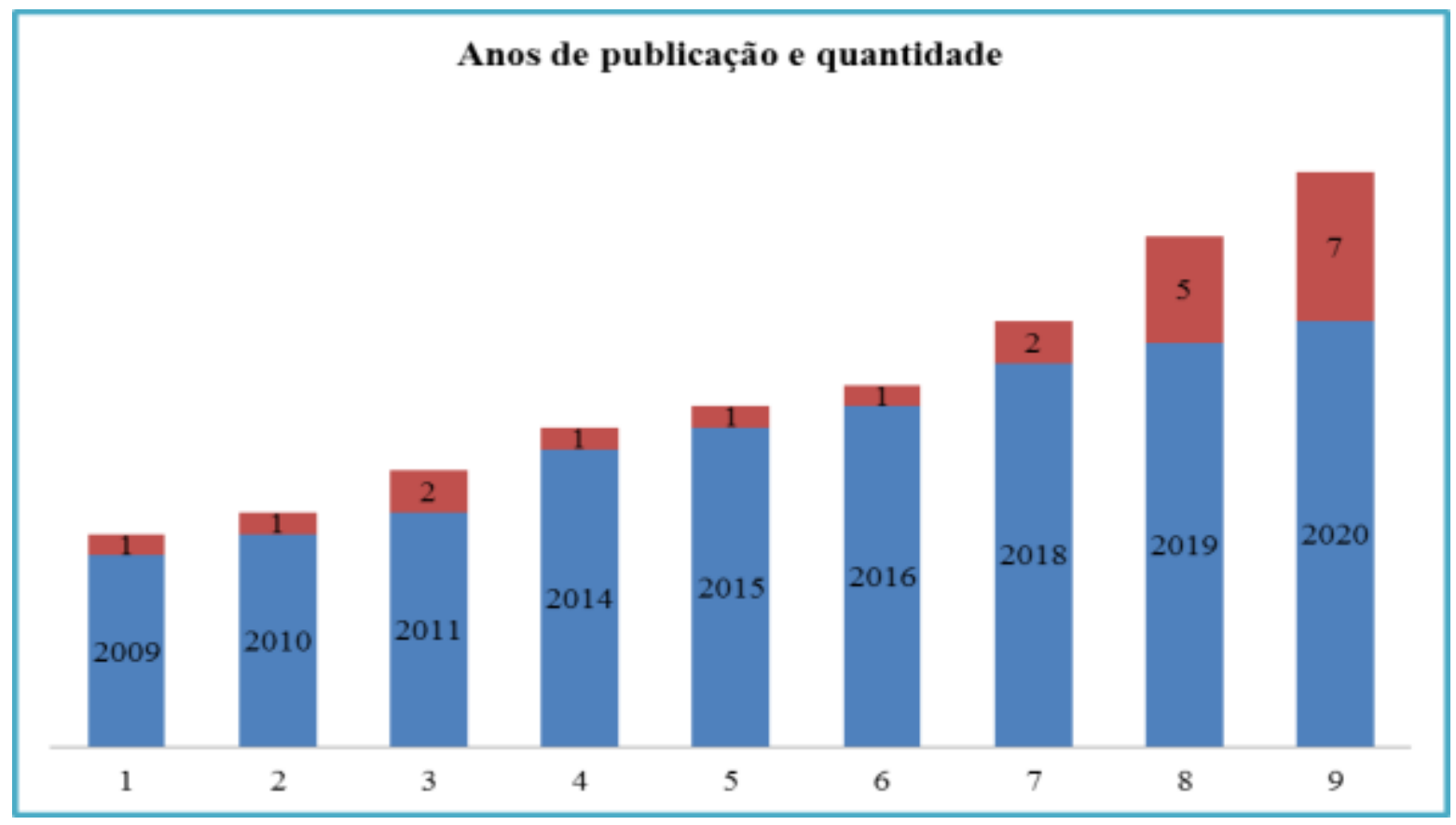

Fonte: Autores (2021).

Ao analisar o gráfico representado acima, observa-se os anos de publicação e a quantidade de artigos publicados, nota-se que no ano de 2009 ocorreu (1) publicação, 2010 (1), 2011 (2), 2014 (1), 2015 (1), 2016 (1), 2018 (2), 2019 (5), 2020 (7). Assim, totalizando 21 artigos publicados e selecionados para serem utilizados na elaboração do presente estudo.

Gráfico 4. Distribuição dos anos de publicação e porcetagem.

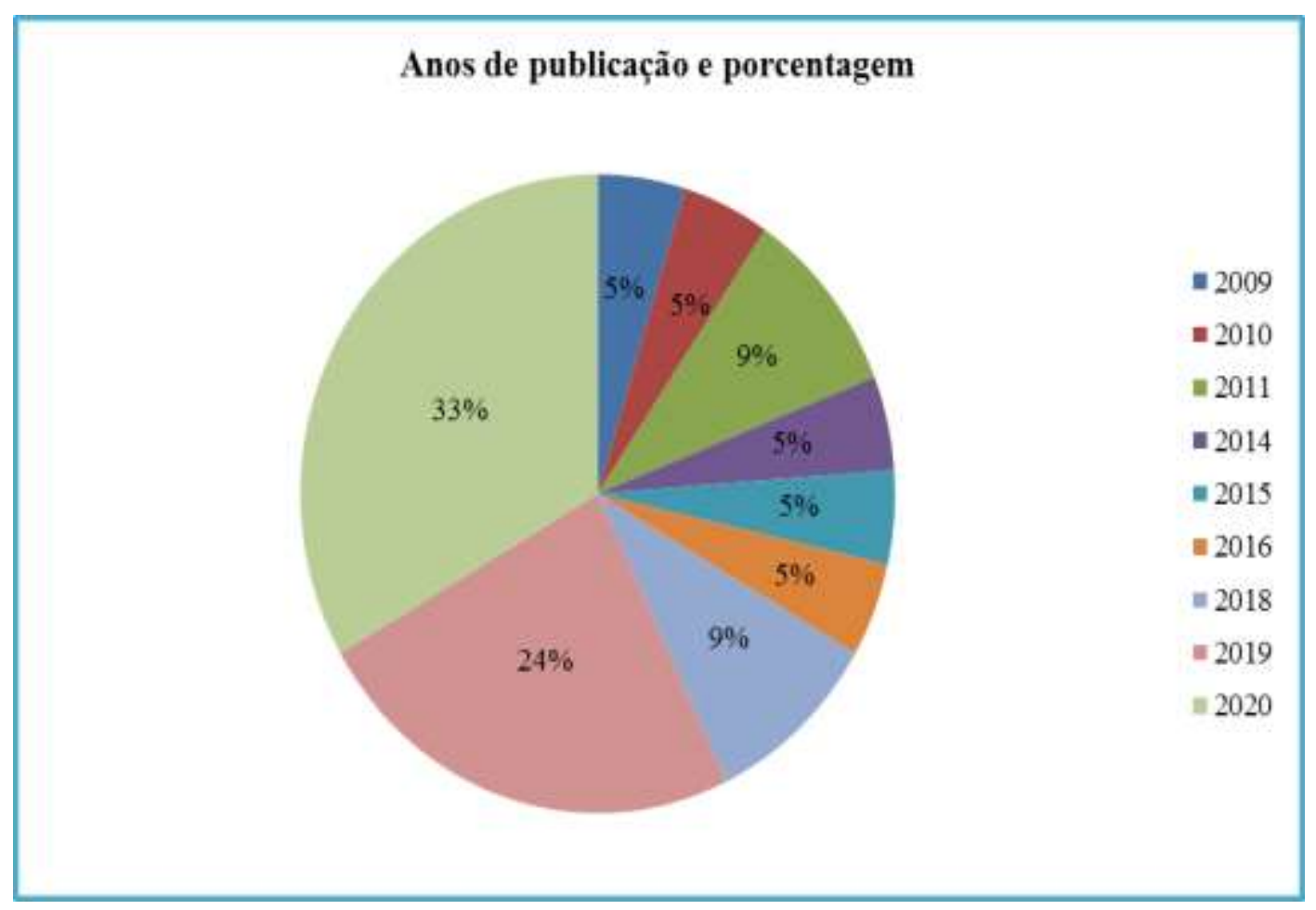

Fonte: Autores (2021). 
Ao verificar o gráfico acima, percebe-se os anos de publicação e porcentagem dos artigos publicados de acordo com cada ano, identifica-se que no ano 2009 ocorreu (5\%) das publicações, 2010 (5\%), 2011 (9\%) 2014 (5\%), 2015 (5\%), 2016 (5\%), 2018 (9\%) 2019 (24\%), e 2020 (33\%), totalizando 100\% das publicações, escolhidas para compor a construção do referido estudo.

Gráfico 5. Distribuição dos artigos conforme os tipos de estudo e quantidade.

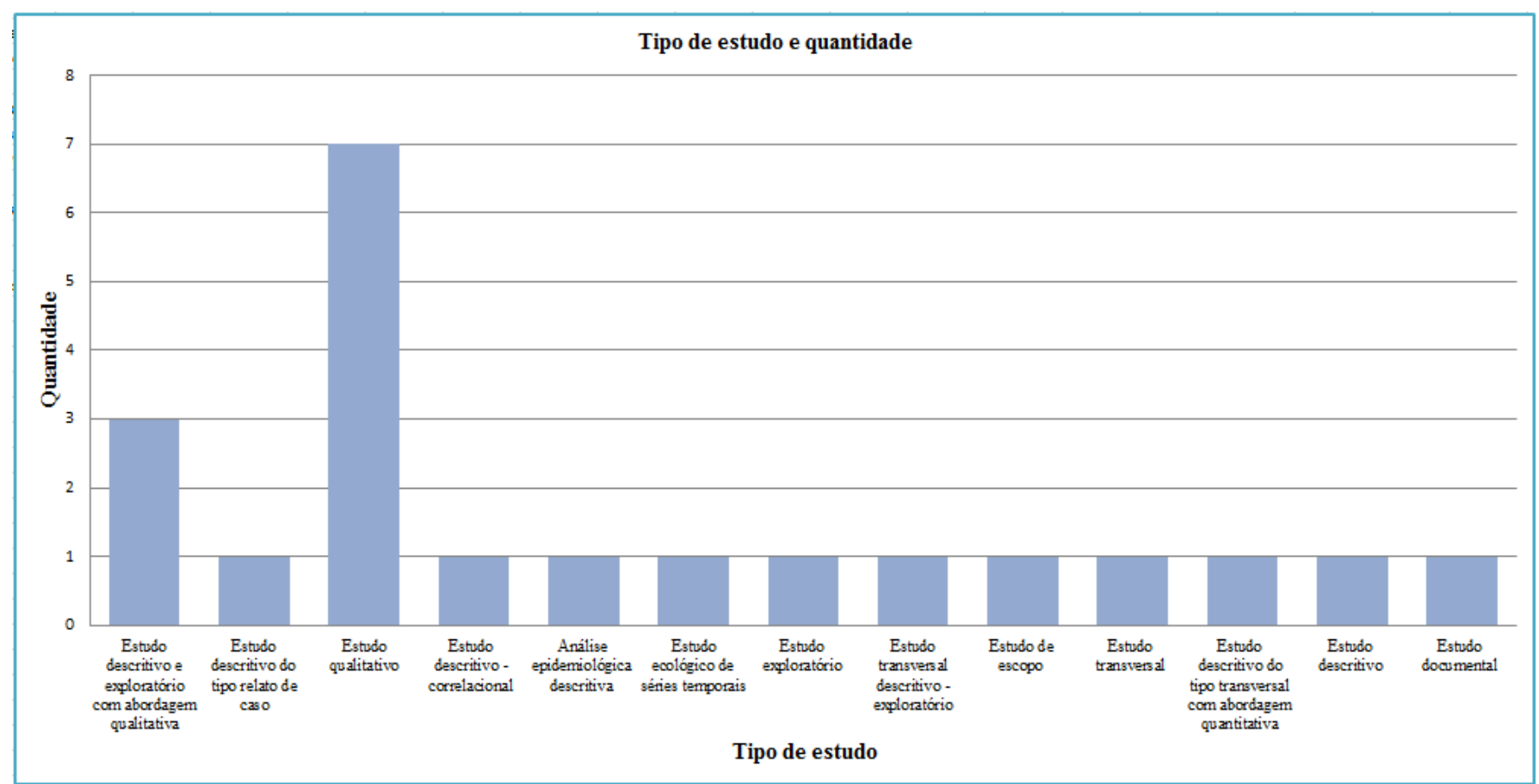

Fonte: Autores (2021).

Ao analisar o gráfico representado acima, identificam-se os tipos de estudo e a quantidade de artigos publicados. Nota-se que, evidenciou-se um total de: estudo descritivo e exploratório, com abordagem qualitativo (3), estudo descritivo do tipo relato de experiência (1), estudo qualitativo (7), estudo descritivo-correlacional (1), análise epidemiológica descritiva (1), estudo ecológico de séries temporais com dados do SIM (1), estudo exploratório (1), estudo transversal descritivo-exploratório (1), estudo de escopo (1), estudo transversal (1), estudo descritivo do tipo transversal com abordagem quantitativa (1), estudo descritivo (1), estudo documental (1) . Totalizando 21 estudos selecionados na amostra final para construção do presente estudo. 
Gráfico 6. Distribuição dos artigos de acordo com as bases de dados e a quantidade de artigos.

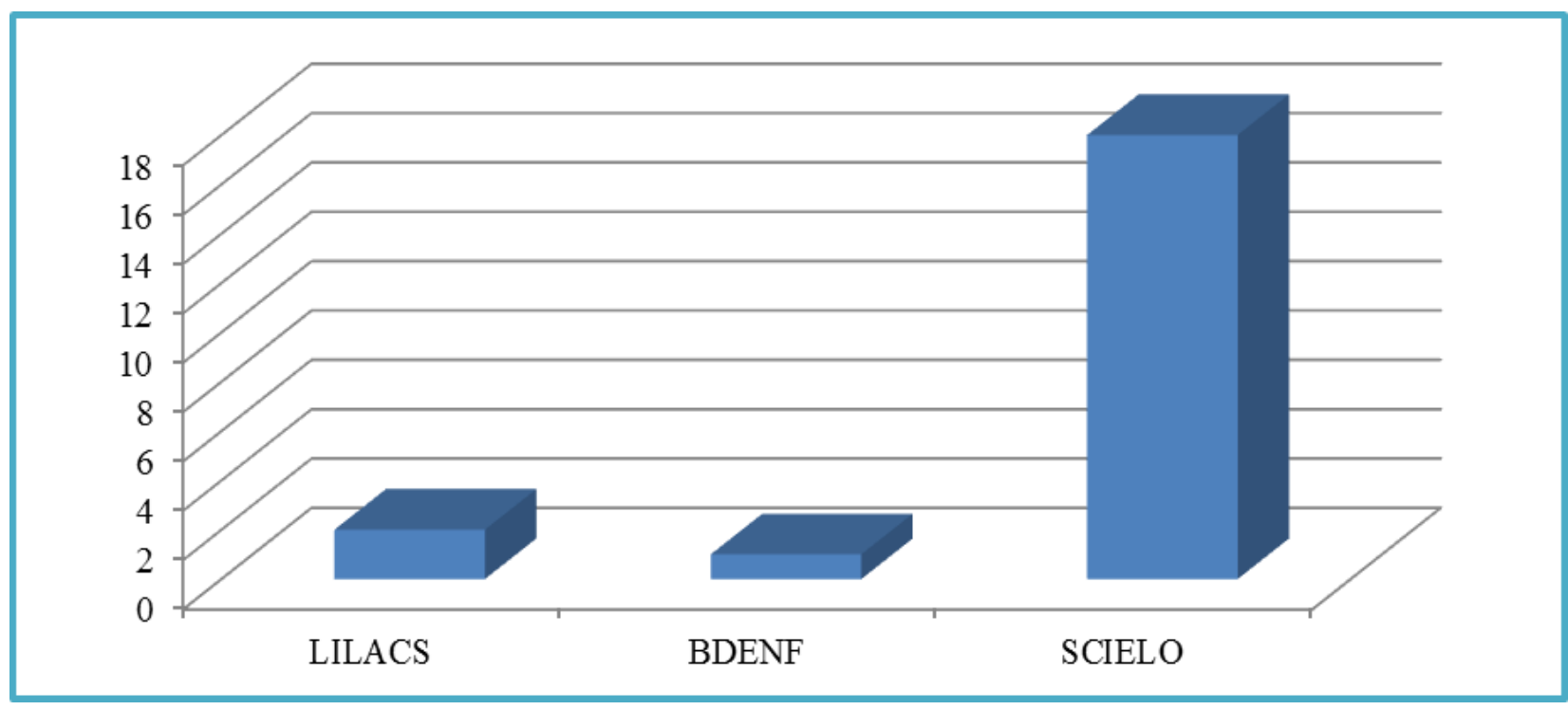

Fonte: Autores (2021).

Segundo o gráfico representado acima é possível identificar as bases de dados e a quantidade de artigo publicados em cada uma. Nota - se que na Literatura Latino-Americana e do Caribe em Ciências da Saúde (LILACS) ocorreu (2) publicações, Base de Dados de Enfermagem (BDENF), (1) e - Scientific Electronic Library Online (SCIELO) (18). Sendo que foram adotados os critérios metodológicos na elaboração do referido estudo.

Gráfico 7. Distribuição dos artigos de acordo com as bases de dados e a porcentagem.

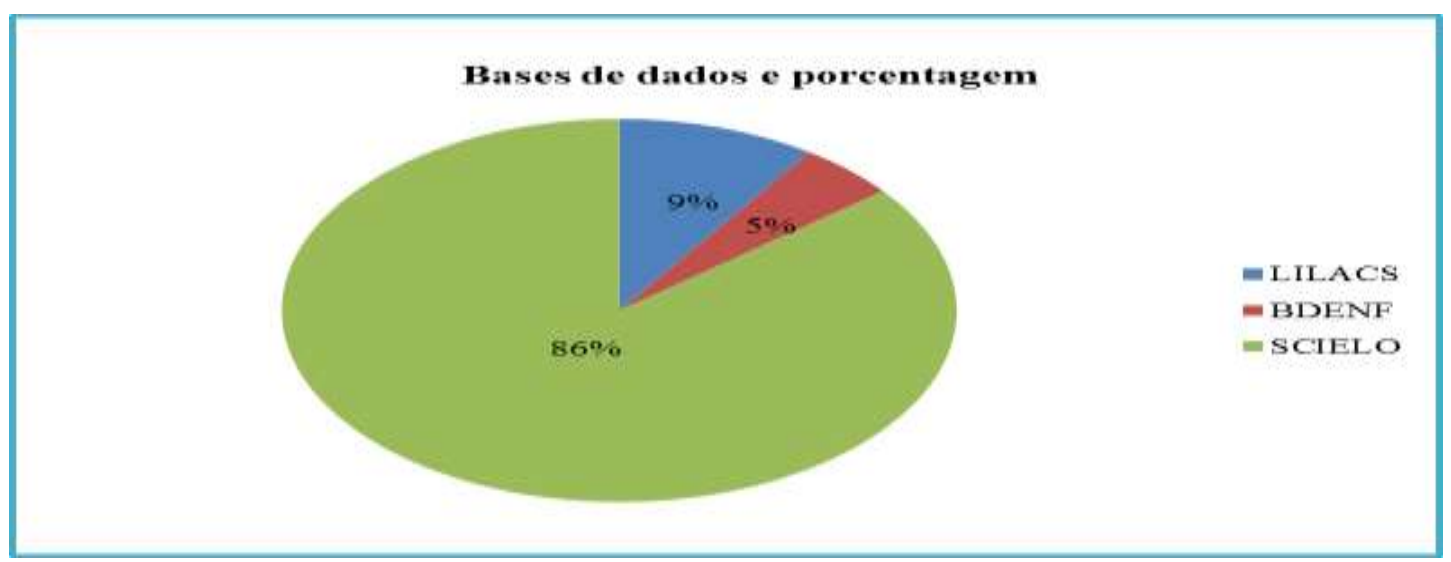

Fonte: Autores (2021).

De acordo com o gráfico ilustrado acima identifica-se as bases de dados e a porcentagem dos artigo publicados em cada uma. Nota - se que na Literatura Latino-Americana e do Caribe em Ciências da Saúde (LILACS) ocorreu (9\%) das publicações, Base de Dados de Enfermagem (BDENF), (5\%) e - Scientific Electronic Library Online (SCIELO) (86\%). Sendo que foram adotados os critérios metodológicos na elaboração do presente estudo.

A adolescência é uma parte do processo natural do crescimento humano, configurando-se como um período em que o adolescente não é adulto, mas também não é considerado mais uma criança. Faz-se necessário que, durante essa fase, o indivíduo amplie e possa desenvolver suas capacidades para adquirir experiências e valores fundamentais para adaptar-se à fase adulta. É nessa etapa que a adolescência pode reverter-se em uma fase de conflitos que, muitas vezes, torna os 
comportamentos arriscados para a vida do indivíduo, incluindo a problemática das ideações suicidas e/ou até mesmo do ato em si (Pessoa et al., 2020).

Assim, identificar que um adolescente carrega dentro de si pensamentos ou ideações suicidas é tarefa complexa, porém é possível. Dessa forma, não só os responsáveis, como a sociedade no geral, precisam atentar-se aos sinais, como: os comportamentos autolesivos e as próprias tentativas de suicídio anteriores. Os comportamentos autolesivos não estão relacionados a uma única causa, mas sim à consequência de complexas influências mútuas entre fatores genéticos, biológicos, psicológicos, sociais e culturais. Desse modo, são atos que não podem ser avaliados isoladamente. Quando o jovem vivencia uma adolescência conflituosa, os comportamentos autolesivos (CAL) aparecem seguidos por um mal-estar psicológico que pode levá-lo a ter pensamentos suicidas. Essa dificuldade de refletir e pensar com muito pessimismo pode caracterizar a ideação suicida. Os determinantes de risco mais ligados ao comportamento suicida são: depressão, ansiedade, sentimentos de solidão, angústia, tristeza, desânimo, abandono físico e emocional, abuso sexual, desestrutura familiar e o término de uma relação amorosa (Pessoa et al., 2020).

A adolescência é uma fase bem característica para o ser humano, nas quais todas as descobertas sobre si, podem se tornar um completo estresse. É exatamente o momento da vida no qual surgem novas experiências para vivenciar o que a juventude tem a oferecer. Os jovens passam por diversas experiências e novas descobertas, como o primeiro emprego e novas amizades, e até mesmo o início de relacionamentos. Neles há o empenho de evidenciar suas qualidades e atributos, e podem encontrar vulnerabilidades, tanto de natureza positiva ou negativa, passando a lidar com situações conflituosas, mudanças e aflições diariamente. Na transição da adolescência para a vida adulta, acontecem mudanças hormonais, físicas e psicológicas, e é exatamente durante essa transição que se tornam perceptíveis as mudanças de humor, comportamento e principalmente a construção de opiniões. Observa-se a concretização de sua pessoalidade, e consequentemente é também nessa fase que alguns conflitos internos ganham força. Muitas vezes se tornam grandes e com cargas maiores que esses jovens conseguem suportar, devido à imaturidade e falta de vivência (Silva, Soares, Sousa, \& Kusano, 2019).

Segundo Schlichting, e Moraes. (2018), durante a fase da adolescência ocorrem acentuadas transformações físicas. A busca por identidade faz do adolescente um ser crítico, inquieto e, muitas vezes insatisfeito já que, enfrenta um novo corpo, tem novas percepções familiares e sociais, e um novo papel na sociedade que se constitui a partir de sua orientação sexual e opção profissional. Além destas particularidades, é um ser ilimitado que está, constantemente, em busca de novos desafios; ao mesmo tempo em que apresenta um perfil ousado é um ser imaturo e vacilante. Essa ambiguidade o coloca em risco constante em função da agilidade das alterações e da alteridade.

$\mathrm{Na}$ transição da adolescência para a vida adulta, acontecem mudanças hormonais, físicas e psicológicas, e é exatamente durante essa transição que se tornam perceptíveis as mudanças de humor, comportamento e principalmente a construção de opiniões. Observa-se a concretização de sua pessoalidade, e consequentemente é também nessa fase que alguns conflitos internos ganham força. Muitas vezes se tornam grandes e com cargas maiores que esses jovens conseguem suportar, devido à imaturidade e falta de vivência (Silva, Soares, Sousa, \& Kusano, 2019).

Segundo Oliveira et al. (2016), os sentimentos mais referidos pelos adolescentes no que diz respeito ao pensamento suicida, são: insegurança, angústia e fragilidade com baixas perspectivas de futuro e medo de repressões familiares, bem como de discriminação social. Outro fato relevante é a causa dessas tentativas de suicídio; a maioria relatou tentar contra a própria vida motivados por conflitos familiares e amorosos.

Entre os adolescentes, de modo geral, os principais fatores de risco para o suicídio são: idade, tentativa prévia, transtorno de humor, depressão, abuso de drogas lícitas e ilícitas, ausência de apoio familiar, história familiar de doenças psiquiátricas, história familiar de comportamento suicida, doença física grave e/ou crônica, eventos estressores, orientação sexual (Abasse, Oliveira, Silva, \& Souza, 2009). 
De acordo com Silva, Vecchia, Ramos, e Costa. (2020), a equipe de enfermagem é responsável pelos cuidados iniciais ao paciente que tenta suicídio, além disso, devido à essência de sua atividade, que é o cuidado, permanece por mais tempo em contato direto com o ser assistido. Ao lado destes pacientes quando adolescentes, tal equipe possui potencialidade para auxiliar na prevenção de novas tentativas de suicídio. Dessa forma, a enfermagem reconhece o suicídio na adolescência como um problema atual e emergente, correlacionam-no com características próprias da adolescência, mas também compreendem que fatores sociais e familiares influenciam na conduta suicida.

Considerando as diversas possibilidades de atuação do enfermeiro, cabe a ele melhor compreender o paciente e sua família como um todo; para isto, precisa estar adequadamente preparado, ser ouvinte atencioso e fornecer suporte profissional e pessoal com vistas a diminuir o sofrimento, angústia e desespero vivenciados por essa família. O cuidado a família do indivíduo que tentou suicídio pode ser construído através de uma linha de apoio emocional, mantendo-a informada e amparada psicologicamente. Com estas práticas o enfermeiro pode ir além de suas rotinas assistenciais estabelecendo assim uma linha de cuidado humanizado a todos os indivíduos participantes deste momento aflitivo, além de ajudar a minimizar o sofrimento e angústia presentes com frequência nestas famílias (Buriola, Arnauts, Decesaro, Oliveira, \& Marcon, 2011).

Quanto ao cuidado de enfermagem, destaca-se a necessidade de qualificar o atendimento por meio da elaboração de protocolos assistenciais para os pacientes e seus familiares. Afinal, a enfermagem deve estar qualificada a prestar um atendimento ético, eficaz, reestabelecendo fisicamente o paciente à medida que fornece apoio psicológico priorizando a escuta qualificada e um cuidado livre de preconceitos ou julgamentos de valor (Oliveira et al., 2016).

É de suma importância que os profissionais da saúde tenham capacitação sobre a temática de suicídio para oferecer um acolhimento e de forma adequada ofertar estratégias capazes de prevenir o suicídio. O mesmo estudo identificou que, por falta de capacitação, alguns profissionais da saúde entendem o ato de tirar a vida como uma afronta aos serviços de saúde. Assim, por ser um problema de saúde pública, é necessário que os profissionais enfermeiros tenham a responsabilidade em procurar conhecimento, capacitação e cobrar dos órgãos gestores atualizações necessárias para saber atuar diante de casos de tentativa de suicídio, tendo o intuito de contribuir com a diminuição destes casos e encorajando o paciente sobre a importância da valorização da vida (Sousa et al., 2019).

Desse modo, os enfermeiros sentem a necessidade de capacitação e treinamento sobre a temática para realização de estratégias a serem desenvolvidas no ambiente de trabalho. Contudo, vale ressaltar que tais profissionais são habilitados para desenvolver métodos de prevenção, considerando-se os recursos existentes na Atenção Básica e o que a Rede de Atenção à saúde dispõe. O Enfermeiro da Atenção Básica possui habilidades, estrutura e conhecimentos que são capazes de ajudar no processo de desenvolvimento de técnicas que possam contribuir com a redução do número de casos de suicídio (Sousa et al., 2019).

A equipe de enfermagem na atenção primária em saúde desempenha ações que buscam a atenção total dos que almejam atendimento. Nesse sentido, os profissionais de enfermagem têm papel muito importante no acolhimento dessas pessoas, trazem segurança para os pacientes e principalmente para a família que fica desolada nesses momentos. Os profissionais enfermeiros ativos no serviço de saúde devem estar preparados e qualificados para identificar as características que o paciente com potencial suicida apresenta. Observar a presença de pensamentos e atitudes que evidenciam desesperança, desespero e desamparo. O paciente com estas características dever ser abordado de forma clara e cautelosa, mantendo a serenidade, a empatia e abstendo-se das atitudes julgadoras (Marçal, \& Gonçalves, 2020).

A enfermagem tem estratégias essenciais que visam melhorar a qualidade de vida do indivíduo que pensa em suicídio, evitando que o pensamento suicida mediante o sofrimento causado pelas questões da vida leve o sujeito a cometer o autoextermínio. $\mathrm{O}$ atendimento primário é fundamental para o reconhecimento de um paciente com ideação suicida, através da entrevista e anamnese o enfermeiro pode identificar indícios físicos e mentais. A equipe de enfermagem ao atender um 
paciente com pensamento suicida deve estar disposta e interessada em ouví-lo, usando o vínculo criado durante a consulta como estratégia para obter a confiança do paciente. O profissional percebe a importância da conciliação entre a equipe e o paciente como estratégia terapêutica em saúde mental para a redução da ação suicida. Investir no espaço agradável e acolhedor, pode fortalecer relações flexíveis, tornando o diálogo mais aberto sobre os sentimentos do paciente e a problemática que envolve o interesse em suicidar (Marçal, \& Gonçalves, 2020).

\section{Conclusão}

Evidenciou-se no estudo, que as prováveis motivações para a ideação suicida, podem ser resultantes de uma gama de fatores de risco como: histórico de suicídio na família, transtornos mentais, exposição à violência, abuso de álcool e drogas, conflitos familiares, além de frustações, rejeições, abuso psicológico, tentativas anteriores de suicídio, problemas disciplinares e baixo rendimento escolar. Além de impulsividade para a resolução dos problemas e escolha de conduta drástica.

Nesse sentido, faz - se necessário que sejam desenvolvidos programas que capacitem profissionais da área da saúde, com a finalidade de auxiliar na identificação prévia destes comportamentos, favorecendo um atendimento adequado, além de atender as demandas apresentadas tanto pelos jovens quanto por suas famílias. Dessa forma, é importante orientar e apoiar familiares, a fim de reduzir angústias e sentimento de impotência. Além disso, apoiar o paciente também é necessário, para que diminua a frequência de pensamentos autolesivos que são prejudiciais à saúde, bem como levar à morte.

Diante desse contexto, é fundamental a aplicação de práticas desenvolvidas especificamente para este público, pois a pessoa que tenta suicídio, ao receber o primeiro atendimento em uma unidade de saúde, encontra-se em um momento de extrema vulnerabilidade. Nesse aspecto, o profissional de enfermagem deve oferecer um atendimento de qualidade ao paciente que deve se sentir acolhido e valorizado. Dispara-se à necessidade de investimento em políticas públicas que supram as carências dos serviços de emergência e saúde mental, visando melhores condições de trabalho para os profissionais em questão, assim como para os usuários além de fortalecer as perspectivas de rede para garantir o acompanhamento dos grupos de risco. Nem todos os casos de suicídio podem ser prevenidos, entretanto muitas vidas serão salvas se todas as pessoas que tentaram o suicídio forem adequadamente abordadas e tratadas.

Entende-se, que os profissionais de enfermagem têm papel muito importante no acolhimento dos pacientes com risco ao suicídio e dos familiares. Para isso utilizam ferramentas e estratégias. São elas a anamnese, o exame do estado mental, a avaliação e a classificação de risco, o acolhimento do paciente em local seguro para ambos, uma rede de apoio juntamente a serviços especializados, familiares/cuidadores e administração de terapia medicamentosa, quando necessário, além de visitas domiciliares. São intervenções flexíveis que passam por revisões periódicas com o propósito de diminuir a quantidade de casos de suicídio por meio de estratégias realizadas nas mais diferentes esferas do cuidado. Torna-se importante a realização de estudos futuros com a finalidade de ampliar a produção científica a respeito dessa temática tão relevante, sendo de suma importância, no sentido de aprofundar discussões que possam contribuir para a promoção da saúde e na melhoria da qualidade de vida desses pacientes.

\section{Referências}

Abasse, M. L. F., Oliveira, R. C. D., Silva, T. C., \& Souza, E. R. D. (2009). Análise epidemiológica da morbimortalidade por suicídio entre adolescentes em Minas Gerais, Brasil. Ciência \& Saúde Coletiva, 14(2), 407-416.

Augusto, C. A., Souza, J. P. D., Dellagnelo, E. H. L., \& Cario, S. A. F. (2013). Pesquisa Qualitativa: rigor metodológico no tratamento da teoria dos custos de transação em artigos apresentados nos congressos da Sober (2007-2011). Revista de Economia e Sociologia Rural, 51(4), 745-764.

Botelho, L. L. R., de Almeida Cunha, C. C., \& Macedo, M. (2011). O método da revisão integrativa nos estudos organizacionais. Gestão e sociedade, 5(11), $121-136$.

Cecconello, A. M. (2019). Fatores de risco e proteção para o suicídio na adolescência. Revista Perspectiva: Ciência e Saúde, 4(2). 
Ercole, F. F., Melo, L. D., \& Alcoforado, C. L. G. C. (2014). Revisão integrativa versus revisão sistemática. Rev Min Enferm, 18(1), 9-12.

Façanha, J. D. N., de Azevedo Erse, M. P. Q., Simões, R. M. P., Amélia, L., \& Santos, J. C. (2010). Prevenção do suicídio em adolescentes: programa de intervenção believe. SMAD, Revista Electrónica en Salud Mental, Alcohol y Drogas, 6(1), 1-16.

Ferenhof, H. A., \& Fernandes, R. F. (2016). Desmistificando a revisão de literatura como base para redação científica: método SSF. Revista ACB, 21(3), 550563.

Fernandes, F. Y., Freitas, B. H. B. M. D., Marcon, S. R., Arruda, V. L. D., Lima, N. V. P. D., Bortolini, J., \& Gaíva, M. A. M. (2020). Tendência de suicídio em adolescentes brasileiros entre 1997 e 2016. Epidemiologia e Serviços de Saúde, 29, e2020117.

Gonçalves, N. D., \& Randemark, N. F. R. (2014). Suicídio na adolescência: representações dos pacientes e suas famílias. ID Online Revista de Psicologia, 8(23), 254-267.

Hildebrandt, L. M., Zart, F., \& Leite, M. T. (2011). A tentativa de suicídio na percepção de adolescentes: um estudo descritivo. Revista Eletrônica de Enfermagem, 13(2), 219-26.

Kern, C., Zanette, C., da Silva Losso, A. R., \& Amboni, G. (2020). Tentativa de suicídio na adolescência: perspectiva psicanalítica. Inova Saúde, 10(1), 103122 .

Lopes, N., Tavares, S., \& Marques, G. Tentativa de suicídio no adolescente: relação enfermeiro adolescente no serviço de urgência.

Magnani, R. M., \& Staudt, A. C. P. (2018). Estilos parentais e suicídio na adolescência: uma reflexão acerca dos fatores de proteção. Pensando familias, 22(1), 75-86.

Mendes, K. D. S., Silveira, R. C. D. C. P., \& Galvão, C. M. (2008). Revisão integrativa: método de pesquisa para a incorporação de evidências na saúde e na enfermagem. Texto \& contexto enfermagem, 17(4), 758-764.

Morais, R. A., \& Lima, V. H. B. (2019). Suicídio na adolescência: um des-compasso na vida. Cadernos de Psicologia, 1(1).

Oliveira, E. N., Felix, T. A., de Lima Mendonça, C. B., Lima, P. S. F., Freire, A. S., \& Moreira, R. M. M. (2016). Aspectos epidemiológicos e o cuidado de enfermagem na tentativa de suicídio. Revista Enfermagem Contemporânea, 5(2).

Pereira, A. S., Shitsuka, D. M., Parreira, F. J., \& Shitsuka, R. (2018). Metodologia da pesquisa científica.

Pessoa, D. M. D. S., Freitas, R. J. M. D., Melo, J. A. L. D., Barreto, F. A., Oliveira e Melo, K. C. D., \& Dias, E. C. D. S. (2020). Assistência de enfermagem na atenção primária à saúde de adolescentes com ideações suicidas. REME rev. min. enferm, e-1290.

Schlichting, C. A., \& Moraes, M. C. L. (2018). Mortalidade por suicídio na adolescência: uma revisão. Revista Família, Ciclos de Vida e Saúde no Contexto Social, 1, 357-363.

Silva, B. M. C., da Silva, J. M., Lima, R. F., de Araújo Costa, R. C. F., \& da Costa, R. S. L. (2019). Internações por tentativa de suicídio entre adolescentes e jovens no Acre de 2008 a 2018. Revista Uningá, 56(4), 113-121.

Silva, G. V. D., Soares, J. B., Sousa, J. C. D., \& Kusano, L. A. E. (2019). Promoção de saúde mental para adolescente em uma escola de ensino médio. Revista do NUFEN, 11(2), 133-148.

Silva, G. V. D., Soares, J. B., Sousa, J. C. D., \& Kusano, L. A. E. (2019). Promoção de saúde mental para adolescente em uma escola de ensino médio-Um relato de experiência. Revista do NUFEN, 11(2), 133-148.

Silva, L. D. L. T., Vecchia, B. P., Ramos, T. M., \& Costa, T. A. F. (2020). Profissionais de enfermagem de um serviço de urgência e emergência frente ao suicídio na adolescência. Revista Eletrônica Acervo Saúde, 12(10), e4042-e4042.

Simões, R., Santos, J. C., \& Martinho, J. (2020). As representações sociais do suicídio em adolescentes: Scoping review. Revista Portuguesa de Enfermagem de Saúde Mental, (23).

Soares, C. B., Hoga, L. A. K., Peduzzi, M., Sangaleti, C., Yonekura, T., \& Silva, D. R. A. D. (2014). Revisão integrativa: conceitos e métodos utilizados na enfermagem. Revista da Escola de Enfermagem da USP, 48(2), 335-345.

Sousa, C. M. D. S., Mascarenhas, M. D. M., Gomes, K. R. O., Rodrigues, M. T. P., Miranda, C. E. S., \& Frota, K. D. M. G. (2020). Ideação suicida e fatores associados entre escolares adolescentes. Revista de Saúde Pública, 54, 33.

Sousa, J. F., de Carvalho Sousa, V., de Carvalho, C. M. S., Amorim, F. C. M., Fernandes, M. A., Coelho, M. C. V. S., \& Soares, J. (2019). Prevenção ao suicídio na atenção básica: concepção de enfermeiros. Revista Cuidarte, 10(2), 4.

Sousa, L. M. M., Marques-Vieira, C. M. A., Severino, S. S. P., \& Antunes, A. V. (2017). A metodologia de revisão integrativa da literatura em enfermagem. No21 Série 2-Novembro 2017, 17.

Souza Marçal, S. R., \& Gonçalves, J. R. (2020). Estratégias de intervenção do enfermeiro diante do comportamento e tentativa de autoextermínio. Revista JRG de Estudos Acadêmicos, 3(6), 56-68.

Souza, M. T. D., Silva, M. D. D., \& Carvalho, R. D. (2010). Revisão integrativa: o que é e como fazer. Einstein (São Paulo), 8(1), $102-106$. 